\title{
Immunoinformatic approach to design a multiepitope vaccine targeting non-mutational hotspot regions of structural and non-structural proteins of the SARS CoV2
}

\author{
Vandana Solanki ${ }^{1}$, Monalisa Tiwari ${ }^{1}$, Vishvanath Tiwari ${ }^{\text {Corresp. } 1}$ \\ ${ }^{1}$ Department of Biochemistry, Central University of Rajasthan, Ajmer, Rajasthan, India \\ Corresponding Author: Vishvanath Tiwari \\ Email address: vishvanath@curaj.ac.in
}

Background: The rapid SARS CoV2 outbreak caused severe pandemic infection worldwide. The high mortality and morbidity rate of SARS CoV2 is due to the unavailability of vaccination and mutation in this virus. The present article aims to design a potential vaccine construct VTC3 targeting the non-mutational region of structural and non-structural proteins of SARS CoV2.

Methods: In this study, vaccines were designed using subtractive proteomics \& reverse vaccinology. To target the virus adhesion and evasion, ten different structural and non-structural proteins have been selected. Shortlisted proteins have been screened for B cell, T cell \& IFN gamma interacting epitopes. 3D structure of vaccine construct was modelled and evaluated for its physicochemical properties, immunogenicity, allergenicity, toxicity, and antigenicity. The finalized construct was implemented for docking and molecular dynamics simulation with different TLRs \& HLAs. The binding energy and dissociation construct of the vaccine with HLA and TLR was also calculated. Mutational sensitivity profiling of the designed vaccine was performed, and mutations were reconfirmed from the experimental database. Antibody production, clonal selection, antigen processing, immune response, and memory generation in host cells after injection of the vaccine was also monitored using immune simulation.

Results: Subtractive proteomics identified seven (structural and non-structural) proteins of this virus that have a role in cell adhesion and infection. The different epitopes were predicted, and only extracellular epitopes were selected that do not have similarity and cross-reactivity with the host cell. Finalized epitopes of all proteins with minimum allergenicity and toxicity were joined using linkers to designed different vaccine constructs. Docking different constructs with different TLRs and HLA demonstrated a stable and reliable binding affinity of VTC3 with the TLRs and HLAs. MDS analysis further confirms the interaction of VTC3 with HLA and TLR1/2 complex. The VTC3 has a favorable binding affinity and dissociation construct with HLA and TLR. The VTC3 does not have similarities with the human microbiome, and most of the interacting residues of VTC3 do not have mutations. The immune simulation result showed that VTC3 induces a strong immune response. The present study designs a multiepitope vaccine targeting the non-mutational region of structural and non-structural proteins of the SARS CoV2 using an immunoinformatic approach, which needs to be experimentally validated. 
1 Title: Immunoinformatic approach to design a multiepitope vaccine

2 targeting non-mutational hotspot regions of structural and non-structural

3 proteins of the SARS CoV2.

4 Vandana Solanki, Monalisa Tiwari, and Vishvanath Tiwari*

5 Department of Biochemistry, Central University of Rajasthan, Bandarsindri, Ajmer-

6 305817, India

7

$8{ }^{*}$ Corresponding Author

9 Dr. Vishvanath Tiwari

10 Department of Biochemistry, Central University of Rajasthan, Bandarsindri, Ajmer-

11 305817, India E-mail: vishvanath@curaj.ac.in; Mobile: + 91-850-300-2573;

12

13 Short Title: Multiepitope vaccine against SARS CoV2

14

15

16

Keywords: Multiepitope vaccine; SARS CoV2; Membrane proteins; ORF8 protein; ORF3a protein; Envelope

17 protein; Surface glycoprotein; ORF1ab polyprotein

18

19

20

21

22

23

Peer) reviewing PDF | (2020:10:53343:1:1:NEW 24 Feb 2021) 


\section{Abstract:}

27 Background: The rapid SARS CoV2 outbreak caused severe pandemic infection worldwide. The high 28 mortality and morbidity rate of SARS CoV2 is due to the unavailability of vaccination and mutation in 29 this virus. The present article aims to design a potential vaccine construct VTC3 targeting the non30 mutational region of structural and non-structural proteins of SARS CoV2.

31 Methods: In this study, vaccines were designed using subtractive proteomics \& reverse vaccinology. To target the virus adhesion and evasion, ten different structural and non-structural proteins have been selected. Shortlisted proteins have been screened for B cell, T cell \& IFN gamma interacting epitopes. 3D structure of vaccine construct was modelled and evaluated for its physicochemical properties, immunogenicity, allergenicity, toxicity, and antigenicity. The finalized construct was implemented for docking and molecular dynamics simulation with different TLRs \& HLAs. The binding energy and dissociation construct of the vaccine with HLA and TLR was also calculated. Mutational sensitivity profiling of the designed vaccine was performed, and mutations were reconfirmed from the experimental database. Antibody production, clonal selection, antigen processing, immune response, and memory generation in host cells after injection of the vaccine was also monitored using immune simulation.

Results: Subtractive proteomics identified seven (structural and non-structural) proteins of this virus that have a role in cell adhesion and infection. The different epitopes were predicted, and only extracellular epitopes were selected that do not have similarity and cross-reactivity with the host cell. Finalized epitopes of all proteins with minimum allergenicity and toxicity were joined using linkers to designed different vaccine constructs. Docking different constructs with different TLRs and HLA demonstrated a stable and reliable binding affinity of VTC3 with the TLRs and HLAs. MDS analysis further confirms the interaction of VTC3 with HLA and TLR1/2 complex. The VTC3 has a favorable binding affinity and dissociation construct with HLA and TLR. The VTC3 does not have similarities with the human microbiome, and most of the interacting residues of VTC3 do not have mutations. The immune simulation result showed that VTC3 induces a strong immune response. The present study designs a multiepitope vaccine targeting the non-mutational region of structural and non-structural proteins of the SARS CoV2 using an immunoinformatic approach, which needs to be experimentally validated. 


\section{Introduction}

57 Immuno-pathogenesis of the infectious epidemic COVID-19 emerged as serious intimidation worldwide. In the Coronaviridae family, among four different coronavirus classes (alpha, beta, delta, and gamma), alpha and beta positive-sense RNA virus strains have been confirmed for broadly epidemic infection (de Wilde et al. 2018; Qamar et al. 2020). SARS CoV2 (Severe Acute Respiratory Syndrome Coronavirus 2) mediated outbreak of the disease was firstly reported in Wuhan city, Hubei province, China, in December 2019 (Gorbalenya et al. 2020; Huang et al. 2020; Perlman 2020; Tahir Ul Qamar et al. 2019; World Health 2020; $\mathrm{Wu}$ et al. 2020; $\mathrm{Zhu}$ et al. 2020). The outbreak has so far infected more than 10,00,000 patients worldwide on dated 10 May 2020. SARS CoV2 genome sequence comparison showed almost 96\%, 79.5\%, and $40 \%$ similarities with bat coronavirus, SARS CoV, and MERS CoV strain, respectively (Alamri et al. 2020; Benvenuto et al. 2020; Zhou et al. 2020). The clinical symptoms of SARS CoV2 exhibit up to 14 days in infected people with fever $\left(\geq 38^{\circ} \mathrm{C}\right)$, diarrhea, dry cough, low peripheral WBC count, respiratory disorder, and low lymphocyte count (Huang et al. 2020). Among SARS CoV2 genomic RNA, 66\% codes for the non-structural or essential proteins, and 33\% codes for the structural or accessory proteins. Non-structural proteins have a significant role in virus replication and transcription in the host cell, while structural proteins cover the outer surface and participate in the host evasion system to cause the infection. SARS CoV2 mutation prone (Jiayuan et al. 2020) genomic organization is a difficult task to develop a vaccine that is composed of 5 -leader-UTR-replicase-ORFabS(Spike)-E(Envelope)-M(Membrane)-ORF6-ORF7a-ORF8-N(Nucleocapsid)-3'UTR-polyA tail. Accessory proteins like ORF3a, ORF7a, and ORF8 are essential for viral pathogenesis (Seema 2020; Zhu et al. 2020).

To overcome the issues such as cost and time mediated traditional method (monoclonal oligonucleotides, small drug molecules), and disease prevention (Li \& De Clercq 2020), the virus was analyzed by computational methods (Chen et al. 2020). Recently published immuno-informatics based vaccine design against MERS virus, Ebola virus chikungunya, and Zika showed the promising potential to fight against disease (Ahmad et al. 2019; Shahid et al. 2020; Tahir Ul Qamar et al. 2018; Tahir Ul Qamar et al. 2019). Reverse vaccinology includes different software algorithms to evaluate the immunological data 
83 toxicity to design the potential multiepitope subunit vaccine (De Gregorio \& Rappuoli 2012; Khan et al. 84 2018; Mirza et al. 2016; Patronov \& Doytchinova 2013). The final multiepitope vaccine is a group of different 85 epitopes joined with the help of linkers that may enhance specific adaptive-immune responses in the host 86 cell (Brennick et al. 2017; Chauhan et al. 2019; Jensen \& Andreatta 2018; Lu \& Meng 2017; Nain et al. 2020;

87 Purcell et al. 2007; Saadi et al. 2017). To activate the host immune system, TLRs' interaction with the 88 designed vaccine could be a potential approach to combat viral infection. Intracellular TLRs that present 89 on cell endosomes interact with ssRNA (TLR-7 \& TLR-8), dsRNA (TLR-3), and CpG DNA (TLR-9) to 90 activate the NFk $\beta$ mediated immune/cell response (Carty \& Bowie 2010). With protein-based epitope 91 vaccine designing, TLR-2, TLR-4, TLR2/6, and TLR1/2 heterodimer mediated immune cell activation 92 (IRF3/7 and NFK $\beta$ ) is an essential factor to activate the innate immunity. Basal TLR-2 and TLR4 activation 93 needs for host protective immunity, whereas its overexpression leads to subvert effect by inducing the viral 94 cell replication in the host cell (Olejnik et al. 2018) hence it is better to target TLR1/2 heterodimer mediated activation signaling with mild TLR-4 interaction/activation (Olejnik et al. 2018).

96 In the present study, non-mutational sequences of SARS-CoV2 were targeted to design a multiepitope 97 vaccine construct. SARS-CoV2 proteome was investigated to identify antigenic proteins, and different T98 cell and B-cell epitopes were identified in selected proteins, and their antigenicity, allergenicity, and 99 physiochemical properties have been evaluated. The molecular docking of final epitope constructs was 100 performed with different TLRs (Toll-Like Receptors), and HLA (human leukocyte antigen) alleles to 101 confirm the stable binding interaction of the multi-epitope vaccine-receptor complex. Vaccine constructs 102 were further assessed for its cross-reactivity and immune response in humans, as well as their similarity 103 with the human microbiome.

\section{2. Materials and Methods}

105 2.1. Protein sequence collection:

106 To evaluate the coronavirus suitable antigenic vaccine target, the different protein sequences have 107 been retrieved from NCBI (https://www.ncbi.nlm.nih.gov/). These proteins are ORF6 protein 108 (YP_009724394.1), membrane glycoprotein (YP_009724393.1), ORF3a protein (YP_009724391.1), 109 nucleocapsid phosphoprotein (YP_009724397.2), ORF10 protein (QHI42199.1), ORF7a protein 110 (YP_009724395.1), envelope protein (YP_009724392.1), ORF1ab (YP_009724389.1), ORF8 protein 111 (QHD43422.1), and surface glycoprotein (YP_009724390.1). All FASTA sequences were used as an input for 112 further immuno-informatics analysis (Seema 2020). 


\section{2.2. Analysis of protein Antigenicity and Trans-membrane helicity}

114 In developing the chimeric multi-epitope vaccine, protein antigenicity and transmembrane helicity 115 play a key role in vaccine successes. To evaluate the protein antigenicity, the Vaxijen server (Doytchinova 116 \& Flower 2007) with 0.4 thresholds has been used, while trans-membrane helicity was estimated using 117 TMHMM (Krogh et al. 2001) and Protter server (Omasits et al. 2014)

\section{2.3. Cytotoxic T cell epitopes prediction with potential antigenicity, allergenicity, and Toxicity:}

119 Shortlisted seven extracellular protein peptides were evaluated by NetCTLpan version 1.1 to predict 120 promiscuous epitopes that can enhance the host cell's immune response by interacting with HLA-epitope 121 binding. NetCTLpan analysis was performed for all MHC (HLA) class I molecules supertype 122 representative (HLA-A01:01, HLA-A02:01, HLA-A03:01, HLA-A24:02, HLA-A26:01, HLA-B07:02, HLA123 B08:01, HLA-B27:05, HLA-B39:01, HLA-B40:01, HLA-B58:01, HLA-B15:01), and predicts the 8, 9, 10, \& 124 11mer peptides to reduce the experimental efforts. With the help of the neural network, the algorithm 125 server has predicted promiscuous high binding affinity nonameric peptides (Stranzl et al. 2010). HLA 126 binder peptides were further evaluated by Vaxijen (http://www.ddg127 pharmfac.net/vaxijen/VaxiJen/VaxiJen.html). AllergenFP (Dimitrov et al. 2013) and Toxinpred server to 128 confirm the epitope's antigenicity, allergenicity, and toxicity level, respectively (Gupta et al. 2013).

\subsection{Immunogenicity prediction:}

130 Immunogenicity prediction (IEDB) confers the property which can elicit the cellular and humoral response in the host cell against viral infection. Shortlisted NetCTLpan epitopes were used for immunogenicity prediction that confers the property which can elicit the cellular and humoral response in

133 the host cell against viral infection. Promiscuous epitopes (ORF3a protein (1 epitope), surface glycoprotein

134 (2 epitopes), and ORF1ab polyprotein (17 epitopes) were used as input peptides for immunogenicity 135 prediction. High binding capacity epitopes (by IEDB immunogenicity tool server) were selected as positive immunogenicity epitopes. This server predicted the immunogenicity level based on the epitope positions

137 in the expected peptide and physicochemical properties of an amino acid (Calis et al. 2013).

\subsection{Helper T cell epitope prediction:}

139 With the help of the IEDB MHC II binding prediction tool, T helper cell epitopes were predicted. In 140 vaccine development, the vaccine must cover most of the world's population. Hence to overcome this HLA 141 alleles variation, a reference set has been used that includes the panel of 27 alleles, which covers the $>99 \%$ 
142 of the population (Greenbaum et al. 2011). IEDB MHC II server is based on a combinational library that

143 generates the percentile rank and IC-50. The lower percentile rank represents a higher affinity of the 144 epitope-HLA complex. The epitope-alleles affinity consensus list was generated for 15 amino acids long 145 epitopes (Wang et al. 2008).

\section{2.6. B cell epitope prediction}

147 B cell epitopes detect viral infections by an antibody-based immune response. IEDB BEPIPRED 148 (Jespersen et al. 2017) and ABCpred (Saha \& Raghava 2006) was used to analyze the B cell interacting 149 epitopes. Overlapped epitopes from both servers were chosen for further analysis. FASTA files of all seven 150 proteins were used as an input file. These resultant epitopes were further screened by Vaxijen, AllergenFP, 151 and TOXINPRED server to analyze the epitope's antigenicity, allergenicity, and toxicity reaction in the host 152 cell.

153

154

155

156

\subsection{Comparative Cross-reactivity, IFN gamma induction analysis of MHC I, II, and B cell epitopes:}

The comparative evaluation of all the finalized MHC I, MHC II \& B cell epitopes has been done to remove the overlapping epitopes. Non-overlapping epitopes should have a unique presence in the virus. To minimize the cross-reactivity in host cells, non-overlapping epitopes were BLAST against human proteome (ID 9606) using Protein Information Resource (Chen et al. 2013). Besides, IFN gamma induction has a vital role in viral elimination and host immune response induction. Hence, we have predicted the IFN gamma induction efficiency of selected non-cross-reactive epitopes via the IFNepitope server (http://crdd.osdd.net/raghava/ifnepitope/).

\section{8. multi-epitope vaccine designing}

All screened epitopes that contain the antigenic property with no allergenicity, toxicity, and crossreactivity have been finalized to design the chimeric multi-epitope vaccine construct against SARS CoV2. A potent vaccine should activate the immune response in the host cell but not activates the detrimental immunity. Hence, to maintain the balance of immunity in the host cell, half non-IFN gamma inducible peptides have been selected, and vice-versa. Epitope binding with B and T cell receptor needs a degree of freedom. Based on the linker's length, flexibility \& rigidity, EAAAK and GGGS linker have been used. EAAAK linkers rigidity is used to maintain spaces between proteins domain while GGGS linkers provide flexibility to construct with minimum linker-epitope interference to maintain the epitope function (Solanki \& Tiwari 2018). 
171

172

173

174

175

176

177

178

179

180

181

182

183

184

185

186

187

188

189

190

191

192

193

194

195

196

197

198

199

\subsection{Evaluation of potential vaccine candidate or construct}

Vaccine constructs binding affinity with B \& T cell, IgE antibody-associated allergic reaction, and post-injection toxicity to host cell are a significant issue in vaccine development. Hence, different vaccine constructs were further investigated for antigenicity (via Vaxijen), allergenicity (via AllergenFP), and toxicity (via Toxinpred). Vaccine constructs physicochemical behaviour analysis is the major key to find out the post-injection symptoms. A highly antigenic vaccine construct (i.e., VTC3) with lower allergic and toxicity has been further evaluated by the Protparam Server (Gasteiger et al. 2003). The web server provides molecular weight (KDa), theoretical isoelectric point (pI), half-life, stability index, aliphatic index, extinction coefficient, and grand average of hydropathicity (GRAVY). The secondary and tertiary structure of selected vaccine construct VTC3 was predicted using PESIPRED (Buchan \& Jones 2019) and Phyre2 in intensive modeling mode (Kelley et al. 2015) respectively. To further cross-validate the model structure, $a b$ initio modeling of the vaccine construct was performed by RaptorX (http://raptorx.uchicago.edu). The modelled vaccine was refined by GalaxyRefine server and validated by PSVS analysis, ProSA (Wiederstein \& Sippl 2007) and QMEAN (Studer et al. 2019) per published protocol.

\subsection{Molecular docking}

The vaccine should induce cell-mediated and humoral immune responses in the host cell to eliminate the virus infection. VTC3 binding studies were performed with TLRs (TLR1, TLR2, TLR3, TLR4, TLR1/2, TLR6) and HLA alleles via molecular docking using PatchDock server ((Schneidman-Duhovny et al. 2005). The docking was further validated by the HDOCK server (http://hdock.phys.hust.edu.cn/) (Yan et al. 2020)

\subsection{Molecular Dynamics Simulation}

The Molecular Dynamics Simulation (MDS) analysis was performed by Desmond using the OPLS3e force field and TIP3P solvent. MDS was run for 50ns in duplicate as per published methods (Tiwari 2021). In brief, the system was built by selecting TIP3P water as a solvent; the system's charge was neutralized by adding twenty-nine sodium ions, the system was made close to the natural system by adding $0.15 \mathrm{M} \mathrm{NaCl}$. The build system was relaxed before simulation, and MDS was performed for 50ns. The MDS trajectories were recorded and analyzed for RMSD and RMSF.

\subsection{Binding affinity and dissociation constant calculation}

The binding affinity as well as dissociation constant of the VTC3 vaccine construct with the HLA and TLRs were further estimated at different simulation time periods using the PRODIGY server (Vangone \& 
200 Bonvin 2017). The MDS trajectories at different time intervals were saved in PDB format and used to

201 calculate the binding affinity and dissociation constant.

202

203

204

205

206

207

208

209

210

211

212

213

214

215

216

217

218

219

220

221

222

223

224

225

226

227

228

\subsection{Validation of potential vaccine candidate or construct with the human microbiome}

Potential vaccine candidate sequence similarity with the gut microflora would unintentionally interfere with the proteins of the host's microflora. To minimize this adverse effect, vaccine candidate VTC3 was BLAST against proteomes of gut flora (226 organisms) (Ramos et al. 2018b) identified in the Human Microbiome Project (Peterson et al. 2009). The BLAST was performed with a significant hit (E-value $\leq 10^{-5}$ ) and identity $\geq 40 \%$ (Ramos et al. 2018a). For further target prioritization, hits with identity $\geq 40 \%$ with a human protein were filtered out, because it could have cross-interference if the virus protein were used as a target.

\subsection{Mutational sensitivity profiling of VTC3 and experimental mutation database analysis}

MAESTROweb server (Laimer et al. 2016) was used for mutational sensitivity profiling of designed multiepitope vaccine construct VTC3. The amino acid sequence of VTC3 was further analyzed for any mutation present in the SARS CoV2 virus with the help of the CoV-GLUE database (update June 2020) using published methods (Tiwari 2020b).

\subsection{Immune Simulations}

Multi epitope vaccine immune simulation profile was performed using C-ImmSim online server (http://kraken.iac.rm.cnr.it/C-IMMSIM/). This server is based on the Celada-Seiden model that predicts the immune (humoral \& cellular) stimulation against vaccine construct (Rapin et al. 2010). The simulation was performed with default parameters like random seed 12345, simulation volume 10, simulation steps 672 , and vaccine injection with no LPS. The parameters were used for vaccine injection with selected MHCs (A0101, B5802, B4403, DRB3_0101, DRB1_0101), and 1000 antigens. The VTC3 vaccine (no LPS) injection was given on $1^{\text {st }}$ day, four weeks, and sixteen weeks (equivalent time steps is 1, 84,336, 504 steps, respectively, where each time step is 8 hours). To further assess the virus clearance capacity of the active immune system, the same antigen is used as a virus and observed that virus elimination. The virus was injected at twenty-four weeks with multiplication factor 0.2 , infectivity 0.6 , and virus number of 1000 . The different immune responses in the host after injection of VTC3 and virus were analyzed from the different plots.

\subsection{Codon adaptation for vaccine construct and in-silico cloning}

Peer) reviewing PDF | (2020:10:53343:1:1:NEW 24 Feb 2021) 
The amino acid sequence of VTC3 was reverse translated to DNA. Codon optimization is important for cloning and expression of VTC3 genes. The Java Codon Adaptation tool (http://www.jcat.de/) was utilized for codon optimization of VTC3 genes in a prokaryotic organism like E. coli. The E. coli K12 strain was selected to enhance the expression efficiency of VTC3. The rho-independent transcription terminators, prokaryotic ribosome binding sites, and cleavage sites of some restriction enzymes were avoided. Sites for restriction endonuclease HindIII and BamHI were added to the $N$ and $C$ terminals of the VTC3 gene, respectively, and subsequently cloned between HindIII and BamHI site of pET28a $(+)$ vector using SnapGene 4.2 tool (https:/snapgene.com/) to ensure the in-vitro expression.

\section{3. Result}

\subsection{Analysis of protein antigenicity and trans-membrane helicity}

The workflow has been discussed in figure 1, which explains the reverse vaccinology mechanism used in the present study. Amino acid sequences of target proteins were collected in FASTA format to analyses antigenicity and trans-membrane helicity. All the proteins with their antigenicity score such as nucleoprotein phosphoprotein (0.50), ORF10 protein (0.71), ORF8 protein (0.65), ORF7a protein (0.64), ORF6 protein (0.61), membrane glycoprotein (0.51), an envelope protein (0.60), ORF3a protein (0.49), surface glycoprotein (0.46), and ORF1ab protein (0.46) showed their potential to exceed the immune response in the host cell. To elicit the host cell's immune response, the transmembrane helicity of viral proteins has been evaluated. With the help of TMHMM and Protter servers, we have identified the extracellular, transmembrane, and cytosolic peptides. The protein protter results showed that nucleoprotein phosphoprotein, ORF6 protein, and ORF10 protein are completely cytosolic. Hence, for further study, these three proteins were eliminated, and the rest of the seven proteins were considered for proteins would help to interact with host PAMPs and maximize the solubility of designed vaccines.

\subsection{Cytotoxic $T$ cell epitopes prediction with potential antigenicity, no allergenicity, and toxicity:}

Cytotoxic T lymphocytes (CTL) epitope predictions of all seven proteins were made using NetCTLpan

2541.1 using the same HLA supertypes. Out of all seven, membrane glycoprotein (YP_009724393.1) did not get any potent HLA binder peptide. The rest six proteins showed the peptide binders with different HLA supertypes. From this server results, we have identified different epitopes ORF8 (8 epitopes), ORF7a 
258 epitopes), and ORF1ab polyprotein (707 epitopes) binders. From the results, we manually screened

259 peptides that showed a binding affinity with more than one HLA allele. This approach will minimize the

260 HLA polymorphism so that promiscuous peptides will show binding to HLA of the wide population. After

261 the manual screening of proteins, we have shortlisted ORF8 (1 epitope), ORF7a protein (2 epitopes),

262 envelope protein (2 epitopes), ORF3a protein (3 epitopes), surface glycoprotein (43 epitopes), and ORF1ab

263 polyprotein (277 epitopes) epitope binders. Based on antigenicity, allergenicity, and toxicity analysis of 264 peptide, different epitopes of ORF8 (0 epitopes), ORF7a protein (0 epitopes), envelope protein ( 0 epitopes),

265 ORF3a protein (1 epitope), surface glycoprotein (2 epitopes), and ORF1ab polyprotein (17 epitopes) were

266 further shortlisted, and the potential epitopes were selected that can enhance immune response via HLA

267 activation (Table1).

268

269

270

271

272

273

274

275

276

277

278

279

280

281

282

283

284

285

286

\subsection{Immunogenicity prediction}

Immunogenicity prediction of ORF3a protein (1 epitope), surface glycoprotein (2 epitopes), and ORF1ab polyprotein (17 epitopes) epitopes had shown the positive score of ORF3a protein (1 epitope), surface glycoprotein (1 epitope), and ORF1ab polyprotein (6 epitopes) epitopes (Table1). The positive immunogenicity with HLA binding confirmed that these epitopes would elicit a high immune response.

\subsection{Helper $T$ cell epitopes prediction with antigenicity, no allergenicity, and toxicity:}

Helper T-cell mediated 15 amino acid extended epitopes were generated against the HLA allele reference set. In results, the percentile rank 0.1 was set as the threshold to filter the HLA interacting epitopes binding affinity. Based on reference threshold, ORF8 (5 epitopes), ORF7a protein (0 epitopes), membrane protein (0 epitopes), envelope protein (0 epitopes), ORF3a protein (0 epitopes), surface glycoprotein (19 epitopes), and ORF1ab polyprotein (18 epitopes) showed $<0.1$ percentile rank (Table2). Low percentile epitopes antigenicity (Table 2), allergenicity, and toxicity level (Table3) further shortlisted the epitopes. The compiled results of all the analyses identified surface glycoprotein (12 epitopes), ORF1ab polyprotein (4 epitopes), and ORF8 (3 epitopes) as HLA-II binders with high antigenicity booster and minimum allergenicity and toxicity.

\subsection{B cell epitope prediction with antigenicity, no allergenicity, and toxicity}

Using the IEDB Bepipred server, different epitopes from selected proteins like ORF8 protein (2 epitopes), ORF7a protein (2 epitopes), membrane glycoprotein (1 epitope), envelope protein (1 epitope), ORF3a protein (1 epitope), surface glycoprotein (28 epitopes), and ORF1ab protein (98 epitopes) have been 
287 screened. With ABCpred server-based B cell epitope analysis, the epitope of ORF8 protein (9 epitopes), 288 ORF7a protein (7 epitopes), membrane glycoprotein (1 epitope), envelope protein (3 epitopes), ORF3a protein (2 epitopes), surface glycoprotein (50 epitopes), and ORF1ab protein (20 epitopes) was shortlisted.

290 To filter out the common epitope from both servers, manual screening has been done to shortlist the 291 common overlapped epitopes. This selects different epitopes from Orf8 protein (2 epitopes), ORF7a protein 292 (2 epitopes), membrane glycoprotein (1 epitope), envelope protein (1 epitope), ORF3a protein (1 epitope), 293 surface glycoprotein (16 epitopes), and ORF1ab protein (8 epitopes). These epitopes were selected for the 294 further experiment (Table 4). The screened epitopes were further analyzed for antigenicity, allergenicity, 295 and toxicity (Table 5). This resulted in shortlisting of ORF8 protein (1 epitope), envelope protein (1 epitope), 296 ORF3a protein (1 epitope), surface glycoprotein (9 epitopes), and ORF1ab protein (6 epitopes) epitopes for 297 further study.

298

299

300

301

302

303

304

305

306

307

308

309

310

311

312

313

314

315

316

3.6. Cross-reactivity, IFN gamma induction analysis of MHC I, II, and B cell epitopes:

All finalized MHC I, II, and B cell epitopes were used for comparative analysis (Table 6) to remove the overlapping sequences. In addition to that, cross-reactivity of selected epitopes with humans has been predicated for analyzing similarity between virus protein epitopes and host cells peptide, which eliminates autoimmune reactivity. BLAST result of all selected epitopes against the human proteome showed that no epitopes were found to have cross-reactivity reactions in the host cell. In addition to this, it was seen that in virus-human cell immune response activity, IFN gamma plays an important role. High expression of IFN gamma leads to virus clearance from human cells. IFNepitope server positive score showed the capacity of the epitope to induce the IFN secretion via T cells, which was listed in Table 6. All the selected epitopes were used to design the different vaccine constructs.

\subsection{Analysis of physicochemical properties of selected vaccine construct VTC3}

Designed vaccine constructs VTC1, VTC2, and VTC3 (Table 7), showed antigenic, with no allergenic and toxicity. The physiochemical analysis of highly antigenic vaccine construct VTC3 showed that it has 227 amino acids, a molecular weight of $24 \mathrm{kDa}$, and an instability index of 23.36 that represent the protein's stable nature. VTC3 construct contains the aliphatic and GRAVY index value of 68.72 and -0.455 , respectively. PESIPRED secondary structure analysis of vaccine construct VTC3 showed the $62.56 \%$ alpha helicity, $7.05 \%$ extended strands, $5.73 \%$ beta-turn with $24.67 \%$ random coils. VTC3 tertiary structure has been modeled, refine, and validated by Ramachandran plot that showed $97 \%$ residue in the favoured region (Figure 2). The model has a Z-score of -3.35, and QMEAN of -10.75 (Supplementary figure 1). To 
317 validate Phyre 2 model, the ab initio model was generated using RaptorX. Both models are similar, and the

318 Ramachandran plot of the RaptoX model showed 99\% residue in the favored region. This confirms that

319 phyre2 model is valid hence used for further study.

3.8. Molecular docking analysis confirms the interaction of VTC3 with TLR and HLA.

321 To be effective against SARS-CoV2, a vaccine should have the capacity to activate the immune 322 response of the human host. The virus can subvert the host protein function, which plays a role in host cell 323 invasion or virus persistence. In a previous study, it has been shown that TLRs have an extensive role in 324 pathogen persistence and clearance. Hence, docking analysis was performed, which showed that our 325 construct VTC3 interacts with TLR1/2 complex, TLR1, TLR3, TLR4, TLR6 but has the highest binding 326 affinity with TLR1/2 complex, followed by TLR4 and TLR6 (Table 8). The docked poses are shown in figure 327 3. As mentioned in the introduction, the interaction of VTC3 with TLR1/2 is important for the immune 328 response for viral infection; hence docking results further confirm it. In addition to that, molecular docking 329 of VTC3 with different HLAs (MHCs) has been performed, which was important to induce MHC-I and 330 MHC-II to activate the immune response in the host cell. Best docked TLRs and HLA alleles molecules 331 were further confirmed by the HDOCK server (supplementary figure SF2). The binding affinity and 332 dissociation constant of VTC3 were favorable with HLA, TLR1/2, and TLR4 (Supplementary Table ST1).

333 3.9. Molecular dynamics simulation (MDS) analysis confirms the strong interaction of VTC3 with TLR1/2

334 heterodimer and HLA.

335 Binding affinity from the PatchDock result showed that VTC3 has better interaction with the TLR1/2 336 complex than TLR4, while Binding affinity from HDOCK result showed TLR4 have better interaction than 337 TLR1/2; hence both complexes were analyzed by MDS analysis. MDS was performed till 10ns for both the 338 complex, and results were analyzed for RMSD, RMSF, etc. RMSD calculation showed that the VTC3-TLR1/2 339 complex is stable throughout simulation with RMSD of around $3 \AA$ (Figure 4A), and the VTC3-TLR4 was 340 found to be relativity less stable with RMSD 7Å (Figure 4C). Similarly, the RMSF analysis showed that the 341 VTC3-TLR1/2 complex has less fluctuation with RMSF of around 3Å (Figure 4B) while the VTC3-TLR4

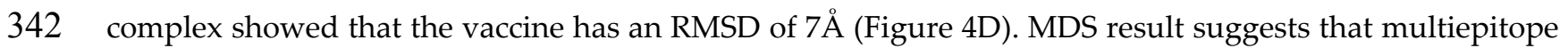
343 vaccine construct VTC3 showed a stronger and stable interaction with TLR1/2 complex compared to TLR4

344 (Figure 4); this indicated that this vaccine construct induces an immune response suitable for clearance of 345 SARS CoV2. For a vaccine construct, it is also important to interact with HLA. MDS analysis of the VTC3346 HLA complex was investigated till 50ns, and the result was analyzed for RMSD and RMSF. RMSD 


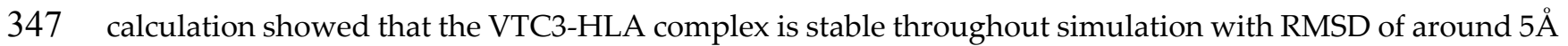

348 at 50ns (Figure 5), and RMSF analysis showed that the VTC3-HLA complex has some fluctuation at the 349 terminal. Both the data suggest the interaction between VTC3 and HLA.

350 3.10. Strong binding affinity and favorable dissociation constant between VTC3 with HLA and TLRs during MDS 351 analysis.

352 To further validate interaction, binding affinity and dissociation constant were calculated for MDS 353 trajectories and found that VTC3 has a binding affinity of $-13.1 \mathrm{kcal} / \mathrm{mol}$ at $45 \mathrm{~ns}$ simulation time and 354 dissociation constant of $2.4 \times 10^{-10} \mathrm{M}$ with HLA at 45ns. Similarity, binding affinity, and dissociation 355 constant of VTC3 was found to be favorable with TLR1/2 (-11.5kcal/mol and 3.8x10-9) and TLR4 (-9.1 kcal/mol 356 and $\left.2.1 \times 10^{-7}\right)$ at $10 \mathrm{~ns}$ simulation time. This showed good interaction between VTC3 with HLA and TLR1/2. 357 The binding affinity and dissociation constant at different simulation times (Supplementary Table ST2) and 358 interacting residues of the VTC3-HLA complex (Supplementary Table ST3) are shown in supplementary 359 data.

3.11. Multiepitope vaccine VTC3 does not have significant similarity with the human gut microbiome.

361 NCBI blast of VTC3 construct against the proteome of 226 gut flora showed no significant similarity 362 (Supplementary Table ST4) between amino acid sequence of the multiepitope vaccine construct VTC3 and 363 amino acid sequence of the human gut microbiome that further minimize the cross-reactivity in the host 364 cell.

\subsection{Mutational profiling of multiepitope vaccine VTC3 showed less mutation sensitivity}

Mutational sensitivity profiling of the VTC3 vaccine construct (figure 6) showed that only a few epitope residues of VTC3 have $\Delta \Delta \mathrm{G}_{\text {pred }}>0$, suggesting that vaccine construct VTC3 has less mutation sensitivity, which enhances the possibility of vaccine constructs to be effective. Similarly, analysis of vaccine construct VTC3 in the CoV-GLUE database showed less mutation hot spots in our vaccine construct (Supplementary Table ST5). This database contains all replacements, insertions, and deletions, which have been observed in the GISAID hCoV-19 sequence sampled from the pandemic. Interacting residues of

373 most of the residues of VTC3 with the mutation do not involve the physical interaction with these proteins.

374 These results further support the efficacy of the vaccine construct.

375 3.13. Immune simulation confirms the strong immune response against the VTC3, as well as virus protection 
In the presence of antigen, the C-ImmSim model illustrates the host immune responses at both the

377

378

379

380

381

382

383

384

385

386

387

388

389

390

391

392

393

394

395

396

397

398

399

400

401

402

403

404

405

humoral and the cellular level. The immune response against the VTC3 vaccine showed an appropriate immune response and virus antigen elimination (Figure 7). Injection of the vaccine VTC3 without LPS shows elevated IgM level was observed after the first injection. Its concentration further increases along with IgG1 after subsequent injection of VTC3, showing secondary and tertiary immune response. The secondary and tertiary response eliminates the antigen on a shorter timescale. It is also observed that when the virus was injected at 24 weeks (at 168days), it is eliminated at the shortest timescale that showed the presence of memory cells to react with virus antigen. It was also observed that after virus injection, IgG1 titer is more than IgM titer (Figure 7A). Similarly, B-cell population increases with subsequent injections of VTCS that show a typical immune response. The memory B cell also increases after $2^{\text {nd }}$ injection and remains almost similar (Figure 7B). The population of Th cells increases after injection of VTC3 and Th memory increase after $2^{\text {nd }}$ injection and remains almost same afterward (Figure 7C). Among the Th cells, the population of Th1 is more dominant. After injection of VTC3, the cytotoxic T cells (TC) population increases and remain constants after first injections with a TC memory (a.u. 900). It was observed that TC memory was further enhanced after injection of the virus at 168days. It was also observed that VTC3 injection increases the IL-12 level, and IFN-gamma showed a potent innate and adaptive immune response. The population of macrophages also increases after the injection of VTC3. Other cells like the dendritic cell (DC), natural killer cells (NK) cells, and epithelial cell population, plasma B lymphocyte (PBL) population also support immune reaction. In brief, the result explains the development of strong immune memory with subsequent virus eliminating potential.

\subsection{Codon adaptation and in silico cloning}

The Java Codon Adaptation tool converted the protein sequence of VTC3 into cDNA sequence. This cDNA sequence contains 52\% GC content and CAI value of 1.0. This high CAI value shows a high expression of the vaccine gene in the host cell. The final vaccine construct (VTC3) was cloned into a pET28a vector between the HindIII and BamHI (Figure 8).

\section{Discussion}

In the present study, a multiepitope vaccine constructs VTC3 for SARS CoV2 have been proposed with the help of reverse vaccinology that compiles the outer surface-exposed epitopes of the structural and nonstructural proteins of this virus. There are different therapeutic strategies, and ongoing research has been tried to control SARS CoV2 (Felsenstein et al. 2020) (Tiwari 2020b) (Tiwari 2020a). Although different

Peer) reviewing PDF | (2020:10:53343:1:1:NEW 24 Feb 2021) 
406 groups have tried to design a vaccine against SARS-CoV2, the present study reports a comprehensive

407 approach to design a vaccine construct that taking care of all possible design shortcomings such as absence 408 of surface epitopes, inappropriate TLRs interactions, less population coverage, interaction with the human 409 microbiome, presence of cross-reactivity with human proteins, epitope form mutation hot spots, and 410 absence of immune response, etc. SARS CoV2 structural proteins like surface glycoprotein, membrane, and 411 envelope protein have a significant contribution in surface adherence and internalization, while non412 structural protein is virulence-associated factors that cause immune-pathogenesis. SARS CoV2 host cell 413 internalization is facilitated by surface glycoprotein (spike protein) interaction with the ACE2 receptor. 414 Targeting the outer exposed peptides of both structural and non-structural protein as a vaccine target 415 would be a promising approach to induce both humoral and cellular immune response that recognizes the 416 virus and killed it. These proteins were shortlisted by antigenicity score and trans-membrane helicity. The 417 shortlisted proteins were used to identify surface-exposed peptides. Surface exposed peptides of these 418 proteins were further analyzed to determine MHC I, II, and B cell-mediated epitopes. The selected epitopes 419 were shortlisted by their antigenicity, allergenicity, toxicity, cross-reactivity, immunogenicity, and IFN 420 gamma secretion scores. Cross-reactivity of selected epitopes of the virus with the human's protein has also 421 predicted that eliminates autoimmune reactivity for the vaccine construct. These epitopes were used to 422 design different vaccine constructs (VTC1, VTC2, and VTC3) with the help of linkers. Antigenicity, 423 allergenicity, and physiochemical analysis of vaccine constructs were further determined to enhance the 424 peptide potency. For designing the reliable vaccine, a mutational hot spot site has been analyzed, and found 425 that epitopes belong to the non-mutation site of the protein. To minimize similarity with human proteome 426 and gut microbiome, BLASTP analysis has been done that showed no similarity of VTC3 construct with 427 host cell proteins.

428 The finalized construct VTC3 should have the potential to interact with pathogen-associated 429 molecular patterns, activates the host's innate immune system, and consonance of the adaptive immunity 430 via TLRs (TLR1, 2, 3, 4, 6, 7, 8, and 9). It has been observed that the TLRs mediated virus interaction not431 only combat virus virulence and infection but also sometimes initiate the host system to overturn 432 downstream signals for the benefit (replication and survival) of the virus-cell. During the viral infection, 433 membrane-associated proteins interaction with TLR2 and TLR4 plays a nuanced role in exceeding 434 inflammatory responses via adhesion and invasion that vitiating the host cell(Olejnik et al. 2018). 435 Simultaneously with TLRs, HLA alleles have a significant contribution to the activation of the robust 436 immune response. The strong HLA-epitope interaction would maintain the signaling cascades to activate 437 the immune response for the viral infection clearance. To prove the modeled VTC3 construct, we have 
438 docked it with different HLAs and TLRs. Presently, the focus lies on the development of vaccines against

439 viruses that can activate the innate immune system via TLR1/2 (Carty \& Bowie 2010; Dowling \& Mansell

440 2016; Jensen et al. 2018) to overcome the subvert effect of the virus on TLR mediated signaling. It is reported

441 that the $\mathrm{CD}^{+}$T cell-mediated HLA allele (HLA-B*5801, PDB ID 5IM7) unique interaction with immune

442 dominant peptide contributes as a potential to control and prevent viral infection (Li et al. 2016). The

443 interaction of VTC3 was investigated with molecular docking and molecular dynamics simulation, and the

444 result is an agreement that the VTC3 construct has the highest affinity for allele HLA-B*5801. It might also

445 create a ray of hope for the potential creation of vaccines or convalescent serum antibodies against SARS

$446 \mathrm{CoV} 2$. Vaccine behaviors in human is a significant concern hence immune simulation was performed that

447 shows strong immune response after injection of VTC3, and virus elimination. The designed multiepitope

448 vaccine construct VTC3 should be tested experimentally for therapeutic potency in future studies.

449 Experimental validation is necessary to demonstrate the potency of the designed vaccine in future studies.

\section{Conclusion}

The high mortality and morbidity rate of COVID 19 is unprecedented due to the unavailability of 452 vaccination; hence effective treatment strategies (inhibitor, drugs, or vaccine), rapid development, trials, and production are needed immediately for this global pandemic disease. To reach out the success, it is necessary to evaluate all possible vaccine candidates to find out the one viable outcome. To increase the chance of success, WHO initiated vaccine solidarity trials to test all vaccine candidates until they fail. In the present study, an attempt was made to design a multi-epitope vaccine against SARS CoV2 that targets its exposed peptides of structural and non-structural proteins. Immunogenicity, allergenicity, toxicity, and potent IFN-gamma inducer scores have also been analyzed to narrow down efficient epitopes further. Peptide matching with the human proteome showed no indication of possible cross-reactivity. However, current reverse immuno-informatics approaches were executed to target surface-exposed proteins for enhancing effective host innate with humoral and cellular immune responses. The present study concludes the design of VTC3 as a multiepitope vaccine against SARS CoV2.

463 Acknowledgments: VT would like to thank the Central University of Rajasthan for providing the 464 Schrodinger suite.

465 Authors contributions: Conceived and designed: VT, Performed the experiments: VS, MT, \& VT. Analyzed 466 the data: VS \& VT, Chemical and Resources provided: VT, Wrote the manuscript: VS, MT, \& VT, Proofread 467 of final version, MT \& VT 
Ethical approval: The present study does not involve human and animal samples.

469 Competing financial interests: The authors have declared that no competing interests exist. The experiment was performed in the absence of any financial support.

Data availability: All the data are available in the manuscript.

472

473

474

475

476

477

478

479

480

481

482

483

484

485

486

487

488

489

490

491

492

493

494

495

496

497

498

499

500

501

502

503

504

505

506

507

508

509

\section{References}

Ahmad B, Ashfaq UA, Rahman MU, Masoud MS, and Yousaf MZ. 2019. Conserved B and T cell epitopes prediction of ebola virus glycoprotein for vaccine development: An immuno-informatics approach. Microb Pathog 132:243-253. 10.1016/j.micpath.2019.05.010

Alamri M, Tahir ul Qamar M, and Alqahtani S. 2020. Pharmacoinformatics and Molecular Dynamic Simulation Studies Reveal Potential Inhibitors of SARS-CoV-2 Main Protease $3 \mathrm{CL}<$ sup $>$ pro $</$ sup $>$. Preprints.org.

Benvenuto D, Giovanetti M, Ciccozzi A, Spoto S, and Angeletti S. 2020. The 2019-new coronavirus epidemic: Evidence for virus evolution. Journal of Medical Virology 92:455-459. 10.1002/jmv.25688

Brennick CA, George MM, Corwin WL, Srivastava PK, and Ebrahimi-Nik H. 2017. Neoepitopes as cancer immunotherapy targets: key challenges and opportunities. Immunotherapy 9:361-371. 10.2217/imt2016-0146

Buchan DWA, and Jones DT. 2019. The PSIPRED Protein Analysis Workbench: 20 years on. Nucleic Acids Research 47:W402-W407. 10.1093/nar/gkz297

Calis JJ, Maybeno M, Greenbaum JA, Weiskopf D, De Silva AD, Sette A, Kesmir C, and Peters B. 2013. Properties of MHC class I presented peptides that enhance immunogenicity. PLoS Comput Biol 9:e1003266. 10.1371/journal.pcbi.1003266

Carty M, and Bowie AG. 2010. Recent insights into the role of Toll-like receptors in viral infection. Clin Exp Immunol 161:397-406. 10.1111/j.1365-2249.2010.04196.x

Chauhan V, Rungta T, Goyal K, and Singh MP. 2019. Designing a multi-epitope based vaccine to combat Kaposi Sarcoma utilizing immunoinformatics approach. Scientific reports 9:2517. 10.1038/s41598019-39299-8

Chen C, Li Z, Huang H, Suzek BE, Wu CH, and Consortium U. 2013. A fast Peptide Match service for UniProt Knowledgebase. Bioinformatics 29:2808-2809. 10.1093/bioinformatics/btt484

Chen Y, Liu Q, and Guo D. 2020. Emerging coronaviruses: Genome structure, replication, and pathogenesis. 92:418-423. 10.1002/jmv.25681

De Gregorio E, and Rappuoli R. 2012. Vaccines for the future: learning from human immunology. Microb Biotechnol 5:149-155. 10.1111/j.1751-7915.2011.00276.x

de Wilde AH, Snijder EJ, Kikkert M, and van Hemert MJ. 2018. Host Factors in Coronavirus Replication. Curr Top Microbiol Immunol 419:1-42. 10.1007/82_2017_25

Dimitrov I, Naneva L, Doytchinova I, and Bangov I. 2013. AllergenFP: allergenicity prediction by descriptor fingerprints. Bioinformatics 30:846-851. 10.1093/bioinformatics/btt619

Dowling JK, and Mansell A. 2016. Toll-like receptors: the swiss army knife of immunity and vaccine development. Clinical \& translational immunology 5:e85-e85. 10.1038/cti.2016.22

Doytchinova IA, and Flower DR. 2007. VaxiJen: a server for prediction of protective antigens, tumour antigens and subunit vaccines. BMC Bioinformatics 8:4. 10.1186/1471-2105-8-4

Felsenstein S, Herbert JA, McNamara PS, and Hedrich CM. 2020. COVID-19: Immunology and treatment options. Clinical immunology (Orlando, Fla) 215:108448-108448. 10.1016/j.clim.2020.108448 
510 Gasteiger E, Gattiker A, Hoogland C, Ivanyi I, Appel RD, and Bairoch A. 2003. ExPASy: The proteomics

511

512

513

514

515

516

517

518

519

520

521

522

523

524

525

526

527

528

529

530

531

532

533

534

535

536

537

538

539

540

541

542

543

544

545

546

547

548

549

550

551

552

553

554

555

556

557 server for in-depth protein knowledge and analysis. Nucleic acids research 31:3784-3788. 10.1093/nar/gkg563

Gorbalenya AE, Baker SC, Baric RS, de Groot RJ, Drosten C, Gulyaeva AA, Haagmans BL, Lauber C, Leontovich AM, Neuman BW, Penzar D, Perlman S, Poon LLM, Samborskiy D, Sidorov IA, Sola I, and Ziebuhr J. 2020. <em>Severe acute respiratory syndrome-related coronavirus</em>: The species and its viruses - a statement of the Coronavirus Study Group. bioRxiv:2020.2002.2007.937862. 10.1101/2020.02.07.937862

Greenbaum J, Sidney J, Chung J, Brander C, Peters B, and Sette A. 2011. Functional classification of class II human leukocyte antigen (HLA) molecules reveals seven different supertypes and a surprising degree of repertoire sharing across supertypes. Immunogenetics 63:325-335. 10.1007/s00251-0110513-0

Gupta S, Kapoor P, Chaudhary K, Gautam A, Kumar R, and Raghava GP. 2013. In silico approach for predicting toxicity of peptides and proteins. PloS one 8:e73957. 10.1371/journal.pone.0073957

Huang C, Wang Y, Li X, Ren L, Zhao J, Hu Y, Zhang L, Fan G, Xu J, Gu X, Cheng Z, Yu T, Xia J, Wei Y, Wu W, Xie X, Yin W, Li H, Liu M, Xiao Y, Gao H, Guo L, Xie J, Wang G, Jiang R, Gao Z, Jin Q, Wang J, and Cao B. 2020. Clinical features of patients infected with 2019 novel coronavirus in Wuhan, China. Lancet 395:497-506. 10.1016/s0140-6736(20)30183-5

Jensen KK, and Andreatta M. 2018. Improved methods for predicting peptide binding affinity to MHC class II molecules. 154:394-406. 10.1111/imm.12889

Jensen KK, Andreatta M, Marcatili P, Buus S, Greenbaum JA, Yan Z, Sette A, Peters B, and Nielsen M. 2018. Improved methods for predicting peptide binding affinity to MHC class II molecules. Immunology 154:394-406. 10.1111/imm.12889

Jespersen MC, Peters B, Nielsen M, and Marcatili P. 2017. BepiPred-2.0: improving sequence-based B-cell epitope prediction using conformational epitopes. Nucleic acids research 45:W24-w29. 10.1093/nar/gkx346

Jiayuan C, Jinsong S, Tungon Y, Chang L, Xin L, Qiang Z, Jishou R, and Gao S. 2020. Bioinformatics analysis of the 2019 novel coronavirus genome. Chinese Journal of Bioinformatics 18:96-102. $10.12113 / 202001007$

Kelley LA, Mezulis S, Yates CM, Wass MN, and Sternberg MJE. 2015. The Phyre2 web portal for protein modeling, prediction and analysis. Nature Protocols 10:845-858. 10.1038/nprot.2015.053

Khan A, Junaid M, Kaushik AC, Ali A, Ali SS, Mehmood A, and Wei DQ. 2018. Computational identification, characterization and validation of potential antigenic peptide vaccines from hrHPVs E6 proteins using immunoinformatics and computational systems biology approaches. PloS one 13:e0196484. 10.1371/journal.pone.0196484

Krogh A, Larsson B, von Heijne G, and Sonnhammer EL. 2001. Predicting transmembrane protein topology with a hidden Markov model: application to complete genomes. J Mol Biol 305:567-580. 10.1006/jmbi.2000.4315

Laimer J, Hiebl-Flach J, Lengauer D, and Lackner P. 2016. MAESTROweb: a web server for structure-based protein stability prediction. Bioinformatics 32:1414-1416. 10.1093/bioinformatics/btv769

Li G, and De Clercq E. 2020. Therapeutic options for the 2019 novel coronavirus (2019-nCoV). Nat Rev Drug Discov 19:149-150. 10.1038/d41573-020-00016-0

Li X, Lamothe PA, Ng R, Xu S, Teng M, Walker BD, and Wang J-H. 2016. Crystal structure of HLA-B*5801, a protective HLA allele for HIV-1 infection. Protein \& cell 7:761-765. 10.1007/s13238-016-0309-y

Lu C, and Meng S. 2017. A novel multi-epitope vaccine from MMSA-1 and DKK1 for multiple myeloma immunotherapy. 178:413-426. 10.1111/bjh.14686

Mirza MU, Rafique S, Ali A, Munir M, Ikram N, Manan A, Salo-Ahen OM, and Idrees M. 2016. Towards peptide vaccines against Zika virus: Immunoinformatics combined with molecular dynamics

Peer) reviewing PDF | (2020:10:53343:1:1:NEW 24 Feb 2021) 
558

559

560

561

562

563

564

565

566

567

568

569

570

571

572

573

574

575

576

577

578

579

580

581

582

583

584

585

586

587

588

589

590

591

592

593

594

595

596

597

598

599

600

601

602

603

604 simulations to predict antigenic epitopes of Zika viral proteins. Scientific reports 6:37313. 10.1038/srep37313

Nain Z, Karim MM, Sen MK, and Adhikari UK. 2020. Structural basis and designing of peptide vaccine using PE-PGRS family protein of Mycobacterium ulcerans-An integrated vaccinomics approach. Mol Immunol 120:146-163. 10.1016/j.molimm.2020.02.009

Olejnik J, Hume AJ, and Muhlberger E. 2018. Toll-like receptor 4 in acute viral infection: Too much of a good thing. 14:e1007390. 10.1371/journal.ppat.1007390

Omasits U, Ahrens CH, Muller S, and Wollscheid B. 2014. Protter: interactive protein feature visualization and integration with experimental proteomic data. Bioinformatics 30:884-886. 10.1093/bioinformatics/btt607

Patronov A, and Doytchinova I. 2013. T-cell epitope vaccine design by immunoinformatics. Open Biol 3:120139. 10.1098/rsob.120139

Perlman S. 2020. Another Decade, Another Coronavirus. N Engl J Med 382:760-762. 10.1056/NEJMe2001126

Peterson J, Garges S, Giovanni M, McInnes P, Wang L, Schloss JA, Bonazzi V, McEwen JE, Wetterstrand KA, and Deal C. 2009. The NIH human microbiome project. Genome research 19:2317-2323.

Purcell AW, McCluskey J, and Rossjohn J. 2007. More than one reason to rethink the use of peptides in vaccine design. Nat Rev Drug Discov 6:404-414. 10.1038/nrd2224

Qamar MTu, Shahid F, Ashfaq UA, Aslam S, Fatima I, Fareed MM, Zohaib A, and Chen L-L. 2020. Structural modeling and conserved epitopes prediction against SARS-COV-2 structural proteins for vaccine development. Research Square.

Ramos PIP, Fernández Do Porto D, Lanzarotti E, Sosa EJ, Burguener G, Pardo AM, Klein CC, Sagot M-F, de Vasconcelos ATR, Gales AC, Marti M, Turjanski AG, and Nicolás MF. 2018a. An integrative, multi-omics approach towards the prioritization of Klebsiella pneumoniae drug targets. Scientific reports 8:10755. 10.1038/s41598-018-28916-7

Ramos PIP, Fernández Do Porto D, Lanzarotti E, Sosa EJ, Burguener G, Pardo AM, Klein CC, Sagot M-F, de Vasconcelos ATR, Gales AC, Marti M, Turjanski AG, and Nicolás MF. 2018b. An integrative, multi-omics approach towards the prioritization of Klebsiella pneumoniae drug targets. Scientific reports 8:10755-10755. 10.1038/s41598-018-28916-7

Rapin N, Lund O, Bernaschi M, and Castiglione F. 2010. Computational immunology meets bioinformatics: the use of prediction tools for molecular binding in the simulation of the immune system. PloS one 5:e9862-e9862. 10.1371/journal.pone.0009862

Saadi M, Karkhah A, and Nouri HR. 2017. Development of a multi-epitope peptide vaccine inducing robust $\mathrm{T}$ cell responses against brucellosis using immunoinformatics based approaches. Infect Genet Evol 51:227-234. 10.1016/j.meegid.2017.04.009

Saha S, and Raghava GP. 2006. Prediction of continuous B-cell epitopes in an antigen using recurrent neural network. Proteins 65:40-48. 10.1002/prot.21078

Schneidman-Duhovny D, Inbar Y, Nussinov R, and Wolfson HJ. 2005. PatchDock and SymmDock: servers for rigid and symmetric docking. Nucleic acids research 33:W363-W367. 10.1093/nar/gki481

Seema M. 2020. T Cell Epitope-Based Vaccine Design for Pandemic Novel Coronavirus 2019-nCoV.

Shahid F, Ashfaq UA, Javaid A, and Khalid H. 2020. Immunoinformatics guided rational design of a next generation multi epitope based peptide (MEBP) vaccine by exploring Zika virus proteome. Infect Genet Evol 80:104199. 10.1016/j.meegid.2020.104199

Solanki V, and Tiwari V. 2018. Subtractive proteomics to identify novel drug targets and reverse vaccinology for the development of chimeric vaccine against Acinetobacter baumannii. Scientific reports 8:9044. 10.1038/s41598-018-26689-7

Stranzl T, Larsen MV, Lundegaard C, and Nielsen M. 2010. NetCTLpan: pan-specific MHC class I pathway epitope predictions. Immunogenetics 62:357-368. 10.1007/s00251-010-0441-4

Peer] reviewing PDF | (2020:10:53343:1:1:NEW 24 Feb 2021) 
605

606

607

608

609

610

611

612

613

614

615

616

617

618

619

620

621

622

623

624

625

626

627

628

629

630

631

632

633

634

635

636

637

638

639

640

641

642

643

644

645

646

647

648

649
Studer G, Rempfer C, Waterhouse AM, Gumienny R, Haas J, and Schwede T. 2019. QMEANDisCodistance constraints applied on model quality estimation. Bioinformatics 36:1765-1771. 10.1093/bioinformatics/btz828

Tahir Ul Qamar M, Bari A, Adeel MM, Maryam A, Ashfaq UA, Du X, Muneer I, Ahmad HI, and Wang J. 2018. Peptide vaccine against chikungunya virus: immuno-informatics combined with molecular docking approach. J Transl Med 16:298. 10.1186/s12967-018-1672-7

Tahir Ul Qamar M, Saleem S, Ashfaq UA, Bari A, Anwar F, and Alqahtani S. 2019. Epitope-based peptide vaccine design and target site depiction against Middle East Respiratory Syndrome Coronavirus: an immune-informatics study. J Transl Med 17:362. 10.1186/s12967-019-2116-8

Tiwari V. 2020a. Denovo designing, retrosynthetic analysis, and combinatorial synthesis of a hybrid antiviral (VTAR-01) to inhibit the interaction of SARS-CoV2 spike glycoprotein with human angiotensin-converting enzyme 2. Biol Open. 10.1242/bio.054056

Tiwari V. 2020b. Novel hybrid antiviral VTRRT-13V2.1 against SARS-CoV2 main protease: retrocombinatorial synthesis and molecular dynamics analysis. Heliyon 6:e05122-e05122. 10.1016/j.heliyon.2020.e05122

Tiwari V. 2021. Denovo designing, retro-combinatorial synthesis, and molecular dynamics analysis identify novel antiviral VTRM1.1 against RNA-dependent RNA polymerase of SARS CoV2 virus. International journal of biological macromolecules 171:358-365. 10.1016/j.ijbiomac.2020.12.223

Vangone A, and Bonvin AMJJ. 2017. PRODIGY: A Contact-based Predictor of Binding Affinity in Proteinprotein Complexes. Bio-protocol 7:e2124. 10.21769/BioProtoc.2124

Wang P, Sidney J, Dow C, Mothe B, Sette A, and Peters B. 2008. A systematic assessment of MHC class II peptide binding predictions and evaluation of a consensus approach. PLoS Comput Biol 4:e1000048. 10.1371/journal.pcbi.1000048

Wiederstein M, and Sippl MJ. 2007. ProSA-web: interactive web service for the recognition of errors in three-dimensional structures of proteins. Nucleic Acids Research 35:W407-W410. 10.1093/nar/gkm290

World Health O. 2020. Surveillance case definitions for human infection with novel coronavirus (nCoV): interim guidance v1, January 2020. Geneva: World Health Organization.

Wu JT, Leung K, and Leung GM. 2020. Nowcasting and forecasting the potential domestic and international spread of the 2019-nCoV outbreak originating in Wuhan, China: a modelling study. Lancet 395:689697. 10.1016/s0140-6736(20)30260-9

Yan Y, Tao H, He J, and Huang S-Y. 2020. The HDOCK server for integrated protein-protein docking. Nature Protocols 15:1829-1852. 10.1038/s41596-020-0312-x

Zhou P, Yang X-L, Wang X-G, Hu B, Zhang L, Zhang W, Si H-R, Zhu Y, Li B, Huang C-L, Chen H-D, Chen J, Luo Y, Guo H, Jiang R-D, Liu M-Q, Chen Y, Shen X-R, Wang X, Zheng X-S, Zhao K, Chen Q-J, Deng F, Liu L-L, Yan B, Zhan F-X, Wang Y-Y, Xiao G, and Shi Z-L. 2020. Discovery of a novel coronavirus associated with the recent pneumonia outbreak in humans and its potential bat origin. bioRxiv:2020.2001.2022.914952. 10.1101/2020.01.22.914952

Zhu N, Zhang D, Wang W, Li X, Yang B, Song J, Zhao X, Huang B, Shi W, Lu R, Niu P, Zhan F, Ma X, Wang D, Xu W, Wu G, Gao GF, and Tan W. 2020. A Novel Coronavirus from Patients with Pneumonia in China, 2019. N Engl J Med 382:727-733. 10.1056/NEJMoa2001017

Peer) reviewing PDF | (2020:10:53343:1:1:NEW 24 Feb 2021) 
650

651

652

653

654

655

656

657

658

659

660

661

662

663

664

665

666

667

668

669

670

671

672

673

674

675

676

677 Figure Legends

678

679

Figure 1. Brief workflow of combinational chimeric multi-epitope vaccine designing with

680 predicted immune cell response. 
681 Figure 2. Tertiary structure of modelled VTC3 construct (A) and Ramachandran plot of the 682 modelled proteins (B).

683 Figure 3. Docked pose of VTC3-TLR1/2 complex (A), and VTC3-TLR4 complex (B).

684

685

686

687

688

689

690

691

692

693

694

695

696

697

698

699

700

701

702

703

Figure 4. Root-mean-square deviation and Root mean square fluctuations during molecular dynamics simulation analysis of VTC3-TLR1/2 complex (A and B), and VTC3-TLR4 complex (C and D).

Figure 5. Root-mean-square deviation during molecular dynamics simulation analysis of VTC3HLA complex. MDS was performed till 50ns.

Figure 6. Diagrammatic presentation of proposed combinational chimeric multi-epitope vaccine VTC3 shows different epitopes and linkers in the vaccine.

Figure 7. Immune Simulation of immunization experiment. Injection of Vaccine VTC3 without LPS was given at $1^{\text {st }}$ Day, $28^{\text {th }}$ Days (4Weeks), 112Days (16Weeks), and injection of the virus after 168Days (24 th week) after initial injection. (A) Antigen counts, and immunoglobulins response in isotypes; (B) B-cell population observed with the administration of VTC3 and virus ; (C) T helper (TH) cells population after injection of VTC3 and virus; D) cytotoxic-T (TC) cells population after injection of VTC3 and virus. The result shows the virus antigen was eliminated at a shorter timescale due to memory cells' presence ready to react against the epitopes.

Figure 8. In silico cloning of the SARS-CoV-2 vaccine in the vector, pET28a (+). Green areas represent the COVID-19 vaccine, while the black areas represent the expression vector, pET28a $(+)$. 
Figure 1

Figure 1

Figure 1. Brief workflow of combinational chimeric multi-epitope vaccine designing with predicted immune cell response.

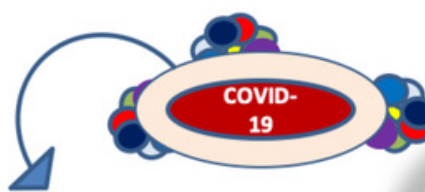

Antigenic property by Vaxilen

Transmembrane

helixity

of protein

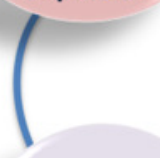

Identification of Outer protein MHC I, II and B cell epitope

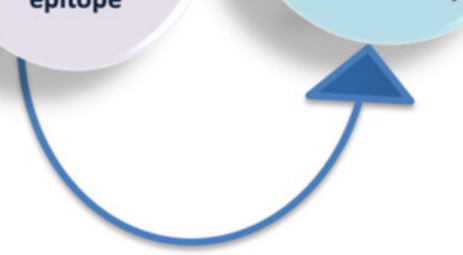

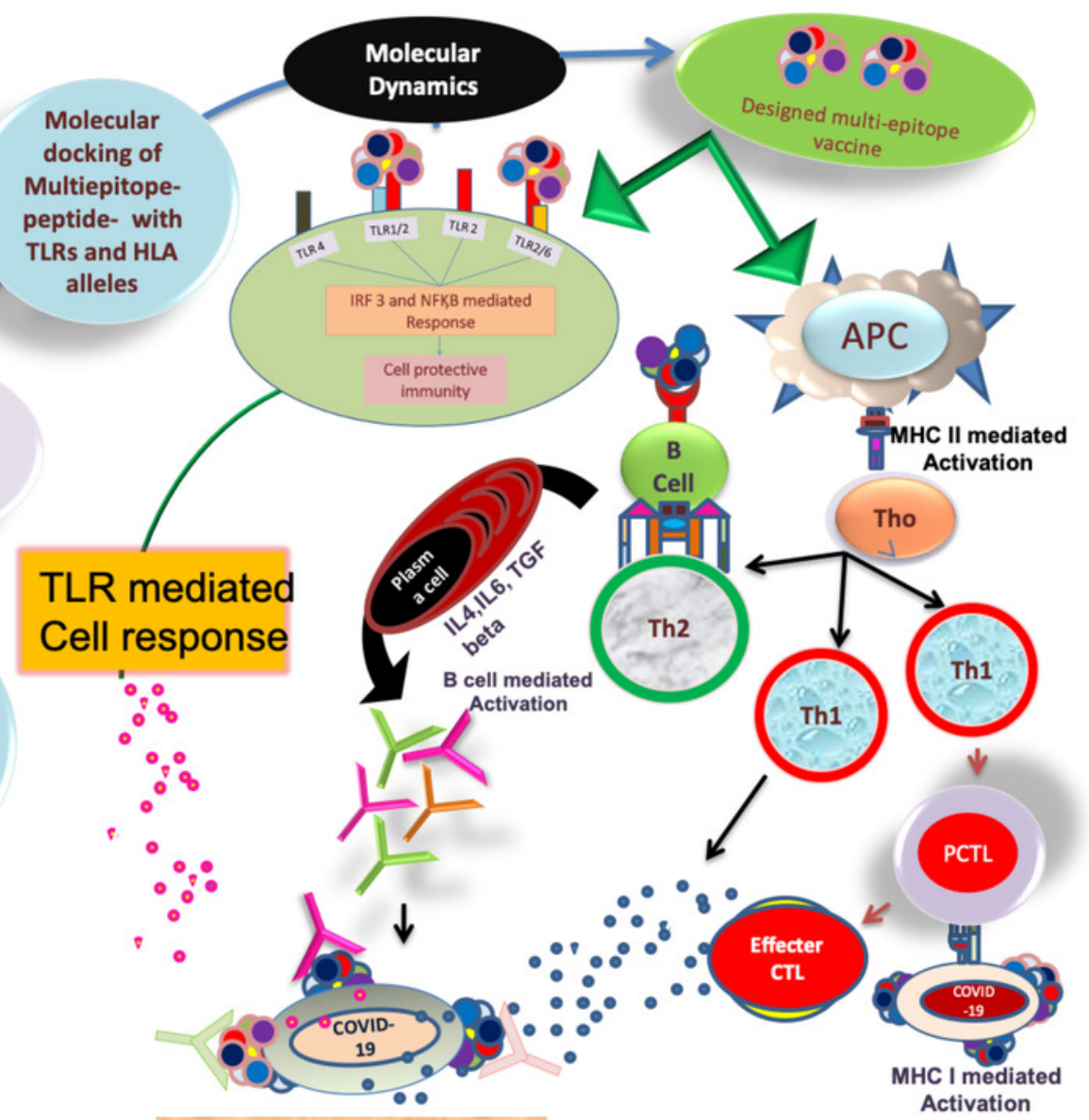

TLRs, MHC I, II \& B cell mediated Cell death of virus 
Figure 2

Figure 2

Figure 2. Tertiary structure of modelled VTC3 construct (A) and Ramachandran plot of the modelled proteins (B).
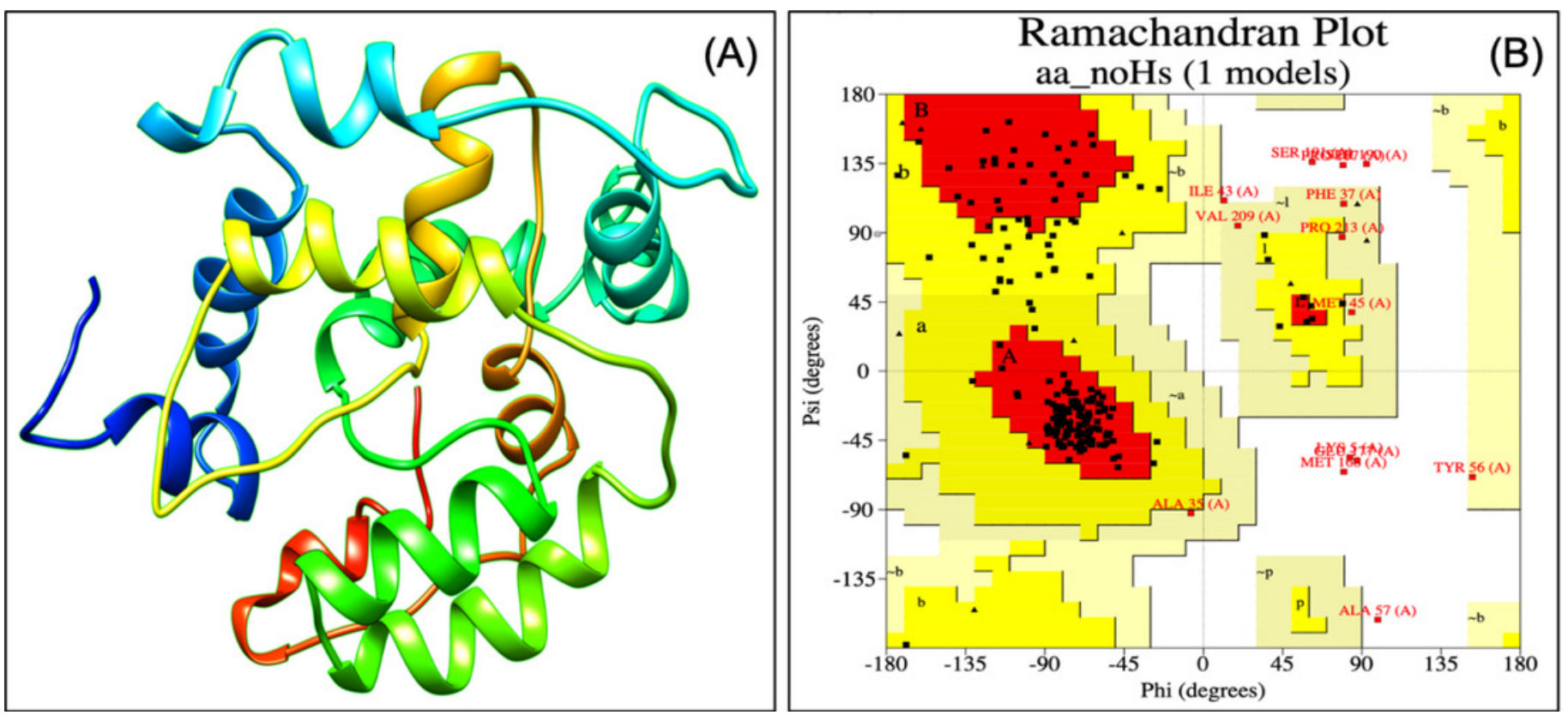
Figure 3

Figure 3

Figure 3. Docked pose of VTC3-TLR1/2 complex (A), and VTC3-TLR4 complex (B).
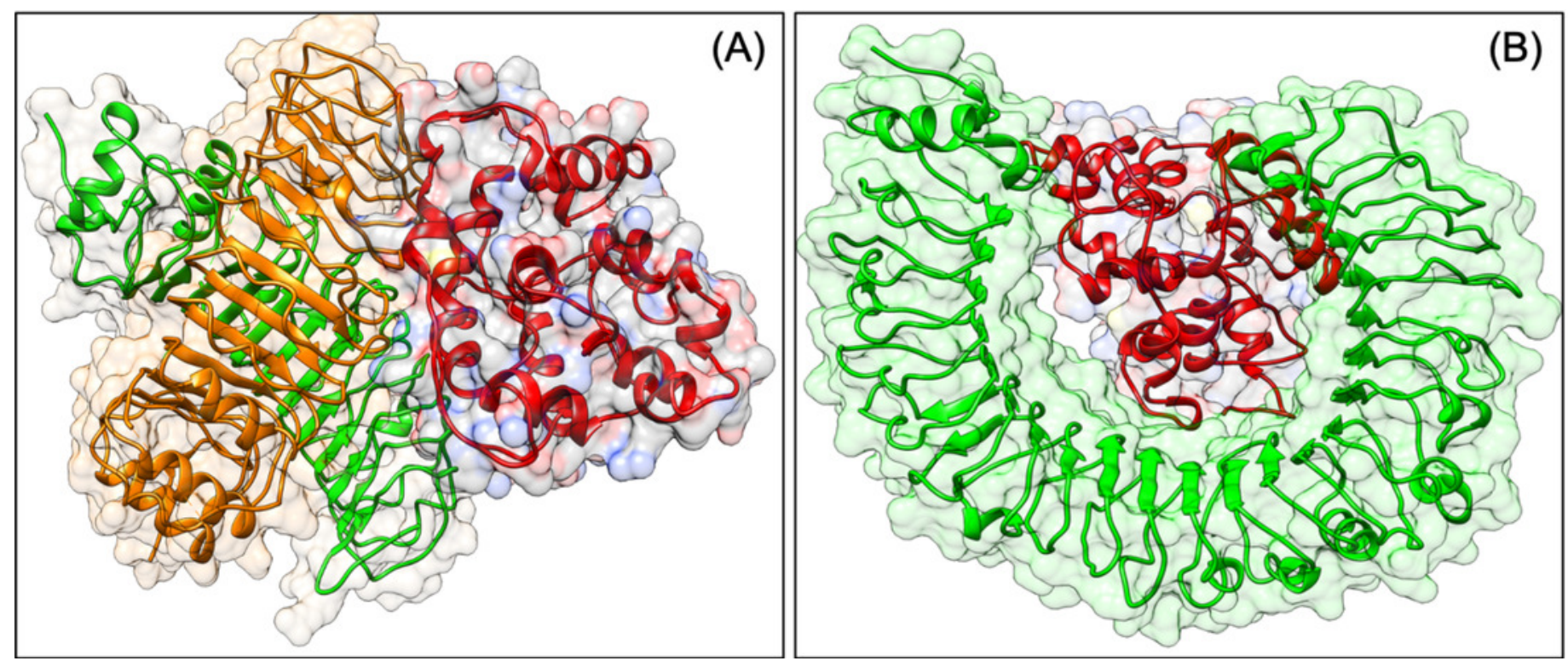
Figure 4

Figure 4

Figure 4. Root-mean-square deviation and Root mean square fluctuations during molecular dynamics simulation analysis of VTC3-TLR1/2 complex (A and B), and VTC3-TLR4 complex (C and D).
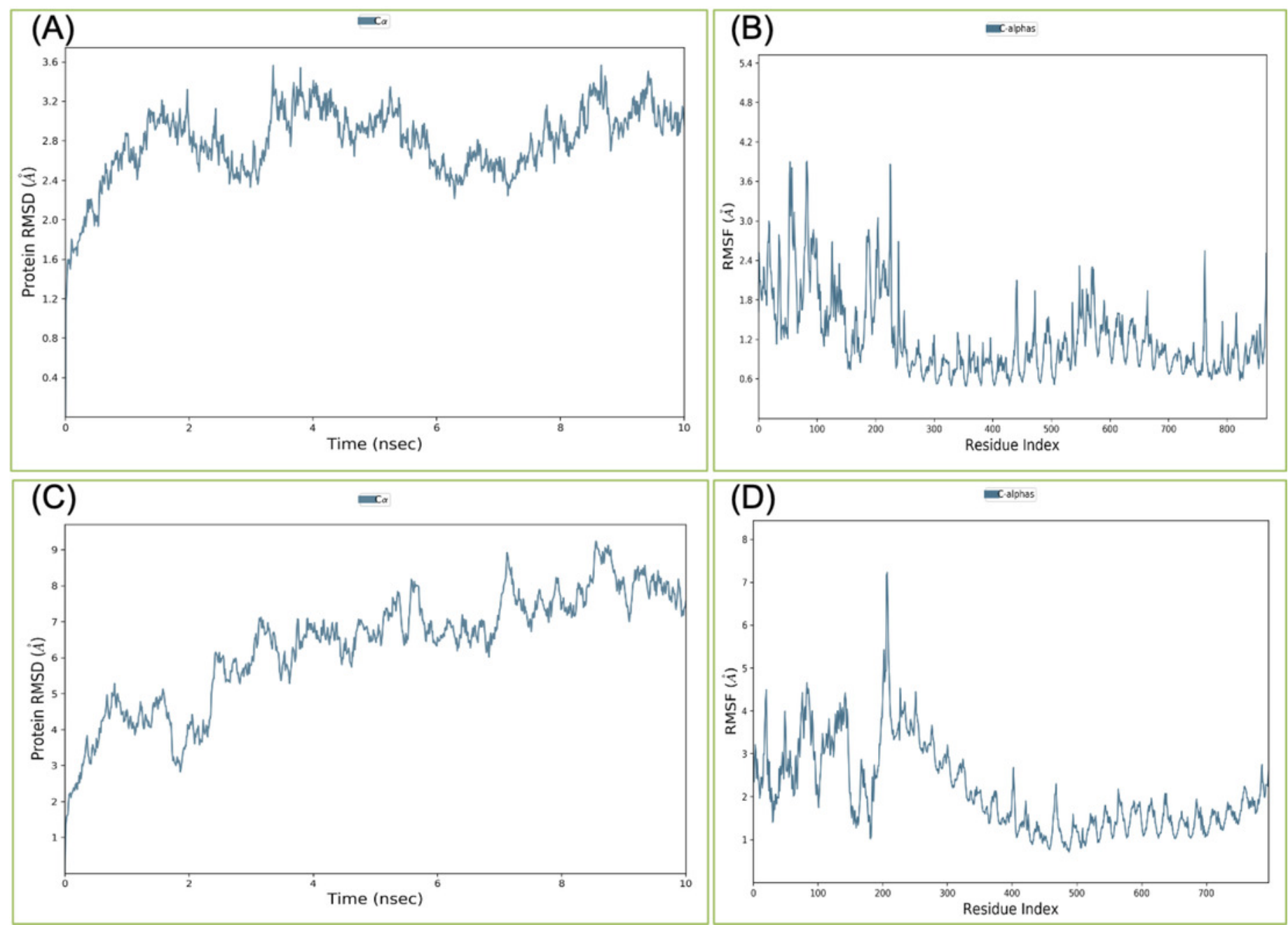
Figure 5

Figure 5

Figure 5. Root-mean-square deviation during molecular dynamics simulation analysis of VTC3-HLA complex. MDS was performed till 50ns.

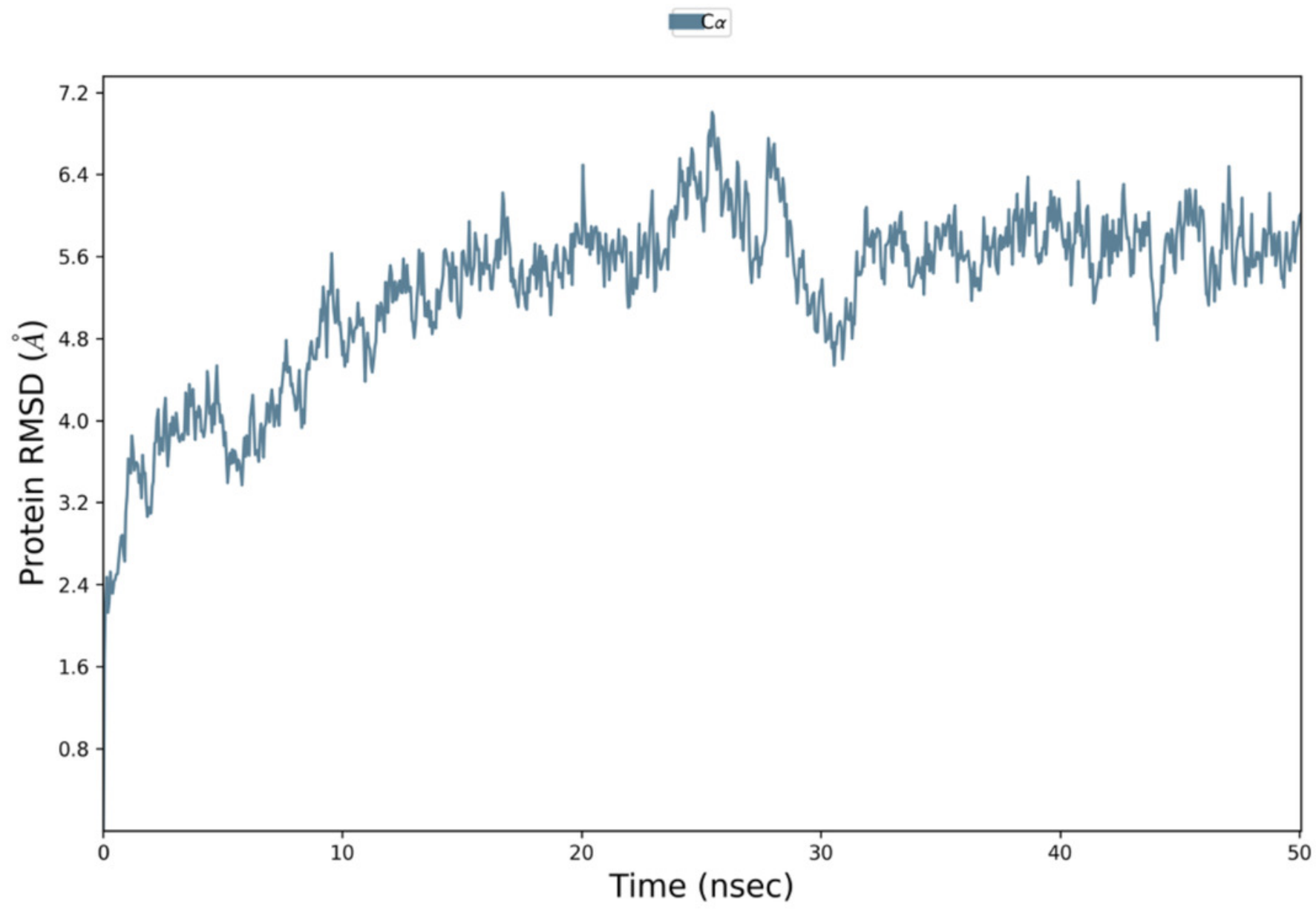




\section{Figure 6}

Figure 6

Figure 6. Diagrammatic presentation of proposed combinational chimeric multi-epitope vaccine VTC3 shows different epitopes and linkers in the vaccine.

\begin{tabular}{|l|l|l|l|l|l|l|l|l|l|l|l|l|l|l|l|l|l|l|l|l|l|l|l|l|l|l|l|l|l|l|l|l|l|l|l|l|}
\hline${ }^{1}$ & 2 & 3 & 4 & 5 & 6 & 7 & 8 & 9 & 1 & 1 & 1 & 1 & 1 & 1 & 1 & 1 & 1 & 1 & 2 & 2 & 2 & 2 & 2 & 2 & 2 & 2 & 2 & 2 & 3 & 3 & 3 & 3 & 3 & 3 & 3 & 3 \\
10 & 0 & 0 \\
\hline
\end{tabular}

\begin{tabular}{|l|l|l|l|l|l|l|l|l|l|l|l|l|l|l|l|l|l|l|l|l|l|l|l|l|l|l|l|l|l|l|l|l|l|l|l|l|}
\hline 3 & 3 & 4 & 4 & 4 & 4 & 4 & 4 & 4 & 4 & 4 & 4 & 50 & 5 & 5 & 5 & 5 & 5 & 5 & 5 & 5 & 5 & 6 & 6 & 6 & 6 & 6 & 6 & 6 & 6 & 6 & 6 & 7 & 7 & 7 & 7 & 7 \\
8 & 9 & 0 & 1 & 2 & 3 & 4 & 5 & 6 & 7 & 8 & 9 & & 1 & 2 & 3 & 4 & 5 & 6 & 7 & 8 & 9 & 0 & 1 & 2 & 3 & 4 & 5 & 6 & 7 & 8 & 9 & 0 & 1 & 2 & 3 & 4 \\
\hline
\end{tabular}

\begin{tabular}{|l|l|l|l|l|l|l|l|l|l|l|l|l|l|l|l|l|l|l|l|l|l|l|l|l|l|l|l|l|l|l|l|l|l|l|l|l|l|}
\hline 7 & 7 & 7 & 7 & 7 & 8 & 8 & 8 & 8 & 8 & 8 & 8 & 8 & 8 & 8 & 9 & 9 & 9 & 9 & 9 & 9 & 9 & 9 & 9 & 9 & 1 & 1 & 1 & 1 & 1 & 1 & 1 & 1 & 1 & 1 & 1 & 1 \\
5 & 6 & 7 & 8 & 9 & 0 & 1 & 2 & 3 & 4 & 5 & 6 & 7 & 8 & 9 & 0 & 1 & 2 & 3 & 4 & 5 & 6 & 7 & 8 & 9 & 0 & 0 & 0 & 0 & 0 & 0 & 0 & 0 & 0 & 0 & 1 & 1 \\
0 & 1 & 2 & 3 & 4 & 5 & 6 & 7 & 8 & 9 & 0 & 1 \\
\hline
\end{tabular}

\begin{tabular}{|l|l|l|l|l|l|l|l|l|l|l|l|l|l|l|l|l|l|l|l|l|l|l|l|l|l|l|l|l|l|l|l|l|l|l|l|l|}
\hline 1 & 1 & 1 & 1 & 1 & 1 & 1 & 1 & 1 & 1 & 1 & 1 & 1 & 1 & 1 & 1 & 1 & 1 & 1 & 1 & 1 & 1 & 1 & 1 & 1 & 1 & 1 & 1 & 1 & 1 & 1 & 1 & 1 & 1 & 1 & 1 & 1 \\
1 & 1 & 1 & 1 & 1 & 1 & 1 & 1 & 2 & 2 & 2 & 2 & 2 & 2 & 2 & 2 & 2 & 2 & 3 & 3 & 3 & 3 & 3 & 3 & 3 & 3 & 3 & 3 & 4 & 4 & 4 & 4 & 4 & 4 & 4 & 4 & 4 \\
2 & 3 & 4 & 5 & 6 & 7 & 8 & 9 & 0 & 1 & 2 & 3 & 4 & 5 & 6 & 7 & 8 & 9 & 0 & 1 & 2 & 3 & 4 & 5 & 6 & 7 & 8 & 9 & 0 & 1 & 2 & 3 & 4 & 5 & 6 & 7 & 8 \\
\hline $\mathrm{G}$ & $\mathrm{P}$ & $\mathrm{H}$ & $\mathrm{E}$ & $\mathrm{Y}$ & $\mathrm{G}$ & $\mathrm{A}$ & $\mathrm{E}$ & $\mathrm{A}$ & $\mathrm{L}$ & $\mathrm{E}$ & $\mathrm{R}$ & $\mathrm{A}$ & $\mathrm{G}$ & $\mathrm{W}$ & $\mathrm{T}$ & $\mathrm{A}$ & $\mathrm{G}$ & $\mathrm{A}$ & $\mathrm{A}$ & $\mathrm{A}$ & $\mathrm{Y}$ & $\mathrm{Y}$ & $\mathrm{E}$ & $\mathrm{A}$ & $\mathrm{A}$ & $\mathrm{A}$ & $\mathrm{K}$ & $\mathrm{L}$ & $\mathrm{K}$ & $\mathrm{Q}$ & 6 & $\mathrm{E}$ & $\mathrm{1}$ & $\mathrm{K}$ & $\mathrm{0}$ & $\mathrm{A}$ \\
\hline
\end{tabular}

\begin{tabular}{|c|c|c|c|c|c|c|c|c|c|c|c|c|c|c|c|c|c|c|c|c|c|c|c|c|c|c|c|c|c|c|c|c|c|c|c|c|}
\hline $\begin{array}{l}1 \\
4 \\
9\end{array}$ & $\begin{array}{l}1 \\
5 \\
0\end{array}$ & $\begin{array}{l}1 \\
5 \\
1 \\
\end{array}$ & $\begin{array}{l}1 \\
5 \\
2 \\
\end{array}$ & $\begin{array}{l}1 \\
5 \\
3\end{array}$ & $\begin{array}{l}1 \\
5 \\
4\end{array}$ & \begin{tabular}{|l|}
1 \\
5 \\
5 \\
\end{tabular} & $\begin{array}{l}1 \\
5 \\
6 \\
\end{array}$ & $\begin{array}{l}1 \\
5 \\
7 \\
\end{array}$ & $\begin{array}{l}1 \\
5 \\
8 \\
\end{array}$ & $\begin{array}{l}1 \\
5 \\
9 \\
\end{array}$ & $\begin{array}{l}1 \\
6 \\
0 \\
\end{array}$ & $\begin{array}{l}1 \\
6 \\
1 \\
\end{array}$ & $\begin{array}{l}1 \\
6 \\
2 \\
\end{array}$ & $\begin{array}{l}1 \\
6 \\
3 \\
\end{array}$ & $\begin{array}{l}1 \\
6 \\
4 \\
\end{array}$ & $\begin{array}{l}1 \\
6 \\
5 \\
\end{array}$ & $\begin{array}{l}1 \\
6 \\
6 \\
\end{array}$ & $\begin{array}{l}1 \\
6 \\
7 \\
\end{array}$ & $\begin{array}{l}1 \\
6 \\
8 \\
\end{array}$ & $\begin{array}{l}1 \\
6 \\
9\end{array}$ & $\begin{array}{l}1 \\
7 \\
0\end{array}$ & $\begin{array}{l}1 \\
7 \\
1 \\
\end{array}$ & \begin{tabular}{l|l|}
1 \\
7 \\
2
\end{tabular} & \begin{tabular}{l|}
1 \\
7 \\
3
\end{tabular} & \begin{tabular}{l|l}
1 \\
7 \\
4
\end{tabular} & $\begin{array}{l}1 \\
7 \\
5 \\
\end{array}$ & $\begin{array}{l}1 \\
7 \\
6\end{array}$ & $\begin{array}{l}1 \\
7 \\
7 \\
\end{array}$ & $\begin{array}{l}1 \\
7 \\
8 \\
\end{array}$ & $\begin{array}{l}1 \\
7 \\
9 \\
\end{array}$ & $\begin{array}{l}1 \\
8 \\
0 \\
\end{array}$ & $\begin{array}{l}1 \\
8 \\
1 \\
\end{array}$ & \begin{tabular}{|l|} 
\\
8 \\
2
\end{tabular} & \begin{tabular}{|l}
1 \\
8 \\
3 \\
\end{tabular} & $\begin{array}{l}1 \\
8 \\
4\end{array}$ & $\begin{array}{l}1 \\
8\end{array}$ \\
\hline & & & & & & & & & & & & LIN & & & & & & & & & ORF & & pro & teir & $n(4)$ & & & & & VKE & & & & & & \\
\hline
\end{tabular}

\begin{tabular}{|l|l|l|l|l|l|l|l|l|l|l|l|l|l|l|l|l|l|l|l|l|l|l|l|l|l|l|l|l|l|l|l|l|l|l|l|l|l|}
\hline 1 & 1 & 1 & 1 & 1 & 1 & 1 & 1 & 1 & 1 & 1 & 1 & 1 & 1 & 2 & 2 & 2 & 2 & 2 & 2 & 2 & 2 & 2 & 2 & 2 & 2 & 2 & 2 & 2 & 2 & 2 & 2 & 2 & 2 & 2 & 2 & 2 \\
8 & 8 & 8 & 8 & 9 & 9 & 9 & 9 & 9 & 9 & 9 & 9 & 9 & 9 & 0 & 0 & 0 & 0 & 0 & 0 & 0 & 0 & 0 & 0 & 1 & 1 & 1 & 1 & 1 & 1 & 1 & 1 & 1 & 1 & 2 & 2 & 2 \\
6 & 7 & 8 & 9 & 0 & 1 & 2 & 3 & 4 & 5 & 6 & 7 & 8 & 9 & 0 & 1 & 2 & 3 & 4 & 5 & 6 & 7 & 8 & 9 & 0 & 1 & 2 & 3 & 4 & 5 & 6 & 7 & 8 & 9 & 0 & 1 & 2 \\
\hline $\mathrm{K}$ & $\mathrm{N}$ & $\mathrm{L}$ & $\mathrm{N}$ & $\mathrm{S}$ & $\mathrm{S}$ & $\mathrm{R}$ & $\mathrm{V}$ & $\mathrm{P}$ & $\mathrm{H}$ & $\mathrm{E}$ & $\mathrm{Y}$ & $\mathrm{G}$ & $\mathrm{A}$ & $\mathrm{E}$ & $\mathrm{A}$ & $\mathrm{L}$ & $\mathrm{E}$ & $\mathrm{R}$ & $\mathrm{A}$ & $\mathrm{G}$ & $\mathrm{P}$ & $\mathrm{Y}$ & $\mathrm{V}$ & $\mathrm{V}$ & $\mathrm{D}$ & $\mathrm{D}$ & $\mathrm{P}$ & $\mathrm{C}$ & $\mathrm{P}$ & $\mathrm{1}$ & $\mathrm{H}$ & $\mathrm{F}$ & $\mathrm{Y}$ & $\mathrm{S}$ & $\mathrm{K}$ & $\mathrm{W}$ \\
\hline
\end{tabular}

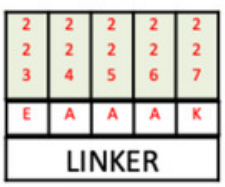




\section{Figure 7}

Figure 7

Figure 7. Immune Simulation of immunization experiment. Injection of Vaccine VTC3 without LPS was given at $1^{\text {st }}$ Day, $28^{\text {th }}$ Days (4Weeks), 112Days (16Weeks), and injection of the virus after 168Days (24 ${ }^{\text {th }}$ week) after initial injection. (A) Antigen counts, and immunoglobulins response in isotypes; (B) B-cell population observed with the administration of VTC3 and virus ; (C) T helper (TH) cells population after injection of VTC3 and virus; D) cytotoxic-T (TC) cells population after injection of VTC3 and virus. The result shows the virus antigen was eliminated at a shorter timescale due to memory cells' presence ready to react against the epitopes. 

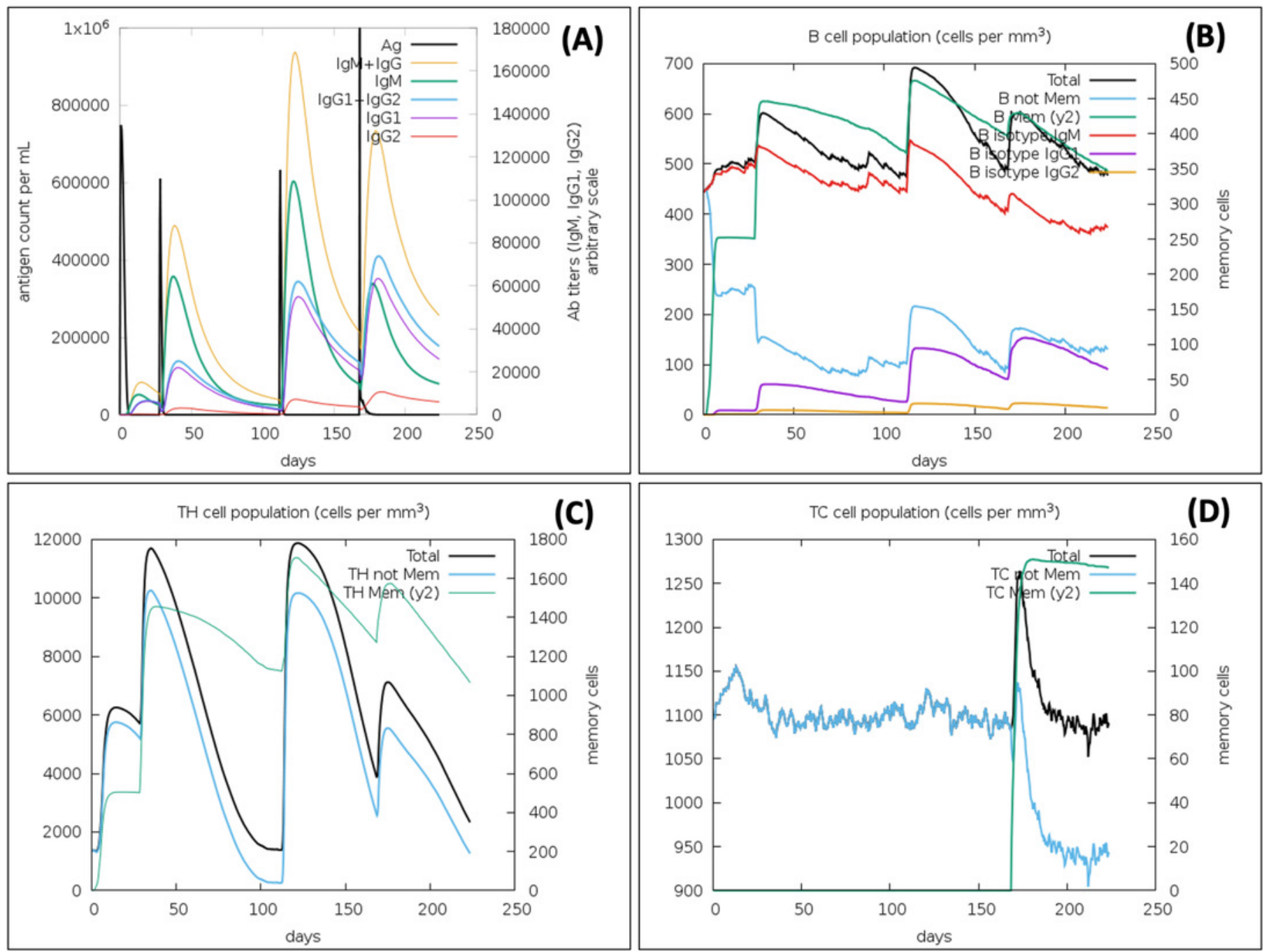
Figure 8

Figure 8

Figure 8. In silico cloning of the SARS-CoV-2 vaccine in the vector, pET28a (+). Green areas represent the COVID-19 vaccine, while the black areas represent the expression vector, pET28a (+).

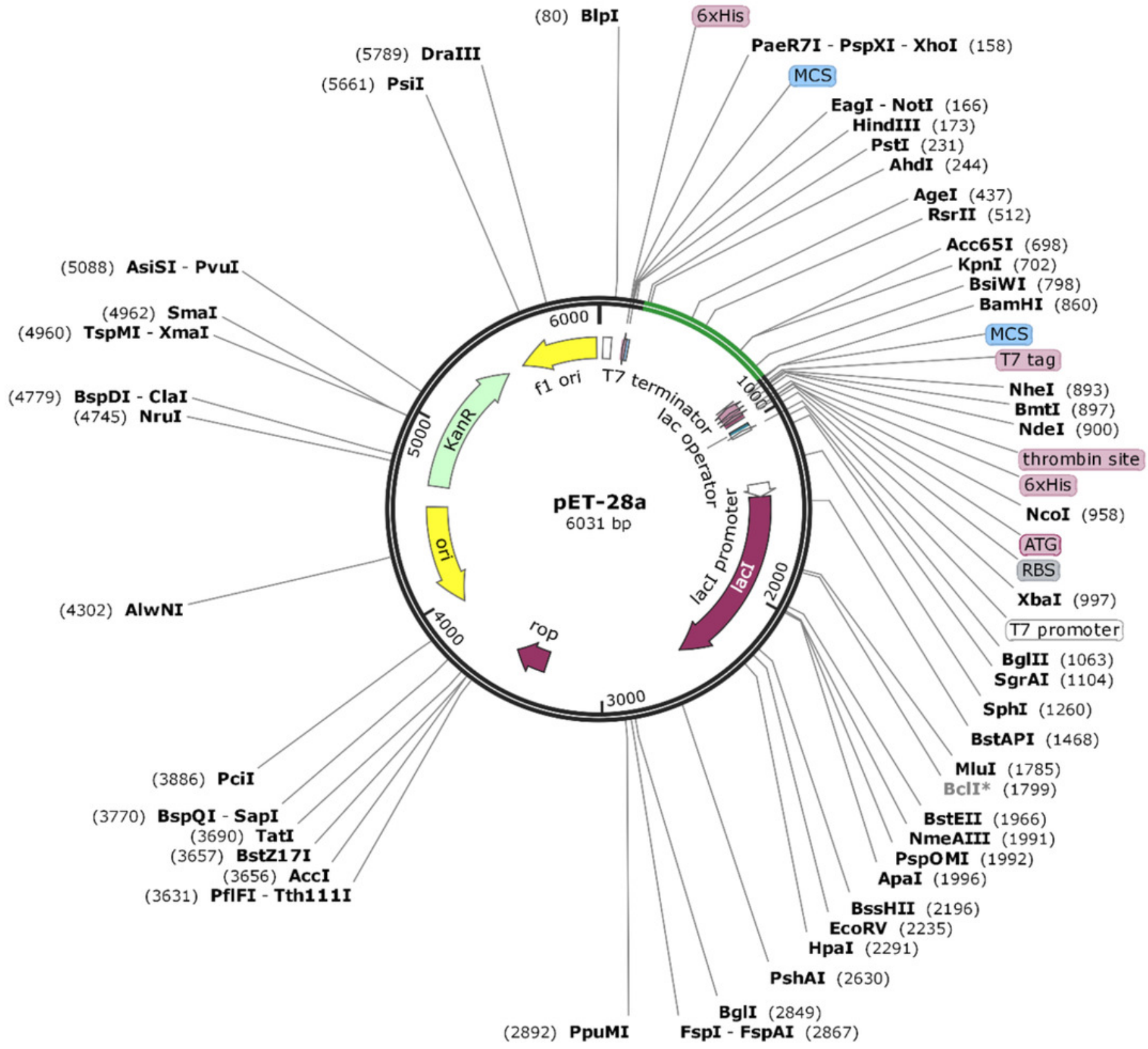




\section{Table $\mathbf{1}$ (on next page)}

\section{Table 1}

Table 1. MHC I binder epitopes positive antigenicity, allergenicity, toxicity and immunogenicity analysis. 
1 Table 1. MHC I binder epitopes positive antigenicity, allergenicity, toxicity and immunogenicity analysis.

\begin{tabular}{|c|c|c|c|c|c|c|c|}
\hline S.No & Protein name & Start & epitope & Antigenicity & Allergenicity & Toxicity & $\begin{array}{c}\text { Immunog } \\
\text { enicity }\end{array}$ \\
\hline 1 & ORF3a & 4 & MRIFTIGTV & 0.69 & Non-allergenic & Non-toxic & 0.37 \\
\hline \multirow{2}{*}{2} & \multirow{2}{*}{ surface glycoprotein } & 242 & WTAGAAAYY & 0.63 & Non-allergenic & Non-toxic & 0.15 \\
\hline & & 702 & FTISVTTEI & 0.85 & Non-allergenic & Non-toxic & -0.18 \\
\hline \multirow{16}{*}{3} & \multirow{16}{*}{ orf1ab polyprotein } & 3449 & LSFKELLVY & 0.72 & Non-allergenic & Non-toxic & -0.07 \\
\hline & & 1890 & EIDPKLDNY & 1.61 & Non-allergenic & Non-toxic & -0.2 \\
\hline & & 1502 & ETISLAGSY & 0.59 & Non-allergenic & Non-toxic & -0.16 \\
\hline & & 3841 & LSDDAVVCF & 0.58 & Non-allergenic & Non-toxic & 0.1 \\
\hline & & 5467 & YTEISFMLW & 1.21 & Non-allergenic & Non-toxic & -0.03 \\
\hline & & 2413 & VVTTFDSEY & 0.45 & Non-allergenic & Non-toxic & 0.1 \\
\hline & & 295 & FMGRIRSVY & 0.52 & Non-allergenic & Non-toxic & 0.125 \\
\hline & & 3471 & LLDKRTTCF & 1.76 & Non-allergenic & Non-toxic & -0.12 \\
\hline & & 4672 & SMMGFKMNY & 1.3 & Non-allergenic & Non-toxic & -0.26 \\
\hline & & 4615 & LQAENVTGL & 0.82 & Non-allergenic & Non-toxic & 0.19 \\
\hline & & 2166 & NYMPYFFTL & 1 & Non-allergenic & Non-toxic & 0.15 \\
\hline & & 5726 & IQLSSYSLF & 0.75 & Non-allergenic & Non-toxic & -0.48 \\
\hline & & 524 & EQKSILSPL & 0.55 & Non-allergenic & Non-toxic & -0.26 \\
\hline & & 5406 & FELEDFIPM & 1.26 & Non-allergenic & Non-toxic & 0.33 \\
\hline & & 724 & EETGLLMPL & 0.48 & Non-allergenic & Non-toxic & -0.12 \\
\hline & & 4055 & KLVLSVNPY & 0.54 & Non-allergenic & Non-toxic & -0.13 \\
\hline
\end{tabular}




\section{Table 2 (on next page)}

Table 2

Table 2. MHC II peptide percentile rank with antigenicity score. 
1 Table 2. MHC II peptide percentile rank with antigenicity score.

\begin{tabular}{|c|c|c|c|c|c|c|}
\hline S.N & Protein Name & Allele & Start & Peptide & $\begin{array}{c}\text { Percentile } \\
\text { rank }\end{array}$ & Antigenicity \\
\hline \multirow{5}{*}{1} & \multirow{5}{*}{ ORF8 protein } & HLA-DRB3*01:01 & 14 & QPYVVDDPCPIHFYS & 0.07 & 0.4574 \\
\hline & & HLA-DRB3*01:01 & 10 & CTQHQPYVVDDPCPI & 0.08 & 0.5165 \\
\hline & & HLA-DRB3*01:01 & 13 & HQPYVVDDPCPIHFY & 0.08 & 0.55 \\
\hline & & HLA-DRB3*01:01 & 12 & QHQPYVVDDPCPIHF & 0.08 & 0.8637 \\
\hline & & HLA-DRB3*01:01 & 11 & TQHQPYVVDDPCPIH & 0.08 & 0.6706 \\
\hline \multirow{21}{*}{2} & \multirow{12}{*}{ surface glycoprotein } & HLA-DRB1*13:02 & 98 & KTQSLLIVNNATNVV & 0.01 & 0.63 \\
\hline & & HLA-DRB1*13:02 & 102 & LLIVNNATNVVIKVC & 0.01 & 0.09 \\
\hline & & HLA-DRB1*13:02 & 100 & QSLLIVNNATNVVIK & 0.01 & 0.43 \\
\hline & & HLA-DRB1*13:02 & 101 & SLLIVNNATNVVIKV & 0.01 & 0.47 \\
\hline & & HLA-DRB1*13:02 & 99 & TQSLLIVNNATNVVI & 0.01 & 0.43 \\
\hline & & HLA-DRB3*02:02 & 100 & QSLLIVNNATNVVIK & 0.02 & 0.43 \\
\hline & & $\begin{array}{c}\text { HLA- } \\
\text { DPA1*01:03/DPB1*04:01 }\end{array}$ & 323 & FGEVFNATRFASVYA & 0.03 & 0.04 \\
\hline & & HLA-DRB1*01:01 & 498 & LSFELLHAPATVCGP & 0.03 & 0.5 \\
\hline & & HLA-DRB1*01:01 & 497 & VLSFELLHAPATVCG & 0.03 & 0.47 \\
\hline & & HLA-DRB1*01:01 & 496 & VVLSFELLHAPATVC & 0.03 & 0.86 \\
\hline & & HLA-DRB1*13:02 & 103 & LIVNNATNVVIKVCE & 0.03 & -0.11 \\
\hline & & HLA-DRB1*13:02 & 97 & SKTQSLLIVNNATNV & 0.03 & 0.62 \\
\hline & & HLA-DRB3*02:02 & 101 & SLLIVNNATNVVIKV & 0.03 & 0.47 \\
\hline & & HLA-DRB3*02:02 & 99 & TQSLLIVNNATNVVI & 0.06 & 0.433 \\
\hline & & $\begin{array}{c}\text { HLA- } \\
\text { DPA1*01:03/DPB1*04:01 }\end{array}$ & 324 & GEVFNATRFASVYAW & 0.07 & -0.12 \\
\hline & & $\begin{array}{c}\text { HLA- } \\
\text { DPA1*01:03/DPB1*04:01 }^{*}\end{array}$ & 322 & PFGEVFNATRFASVY & 0.07 & 0.03 \\
\hline & & HLA-DRB1*01:01 & 499 & SFELLHAPATVCGPK & 0.09 & 0.2 \\
\hline & & HLA-DRB1*01:01 & 495 & VVVLSFELLHAPATV & 0.09 & 0.8 \\
\hline & & HLA-DRB3*02:02 & 102 & LLIVNNATNVVIKVC & 0.09 & 0.09 \\
\hline & & HLA-DRB1*13:02 & 98 & KTQSLLIVNNATNVV & 0.01 & 0.63 \\
\hline & & HLA-DRB1*13:02 & 102 & LLIVNNATNVVIKVC & 0.01 & 0.09 \\
\hline \multirow{17}{*}{3} & \multirow{17}{*}{ orf1ab polyprotein } & HLA-DRB1*09:01 & 54 & AIILASFSASTSAFV & 0.01 & 0.23 \\
\hline & & $\begin{array}{c}\text { HLA- } \\
\text { DQA1*01:02/DQB1*06:02 }\end{array}$ & 45 & AFASEAARVVRSIFS & 0.08 & -0.02 \\
\hline & & HLA-DRB1*07:01 & 10 & CTFTRSTNSRIKASM & 0.12 & -0.02 \\
\hline & & $\begin{array}{c}\text { HLA- } \\
\text { DPA1*03:01/DPB1*04:02 }\end{array}$ & 1 & YFFTLLLQLCTFTRS & 0.16 & -0.37 \\
\hline & & HLA-DRB5*01:01 & 33 & LGRYMSALNHTKKWK & 0.17 & 0.04 \\
\hline & & HLA-DRB1*01:01 & 20 & KSAFYILPSIISNEK & 0.27 & 0.71 \\
\hline & & $\begin{array}{c}\text { HLA- } \\
\text { DPA1*03:01/DPB1*04:02 }\end{array}$ & 2165 & CTNYMPYFFTLLLQL & 0.01 & 0.45 \\
\hline & & HLA-DRB1*01:01 & 1801 & ESPFVMMSAPPAQYE & 0.01 & 0.54 \\
\hline & & HLA-DRB1*09:01 & 474 & AIILASFSASTSAFV & 0.01 & 0.23 \\
\hline & & $\begin{array}{c}\text { HLA- } \\
\text { DPA1*03:01/DPB1*04:02 }^{*}{ }^{*} \text { ( }\end{array}$ & 1244 & EETKFLTENLLLYID & 0.03 & -0.11 \\
\hline & & HLA-DRB3*01:01 & 903 & ATYYLFDESGEFKLA & 0.04 & 0.23 \\
\hline & & 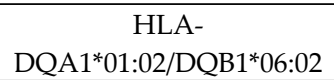 & 535 & AFASEAARVVRSIFS & 0.08 & -0.02 \\
\hline & & HLA-DRB1*15:01 & 747 & AMPNMLRIMASLVLA & 0.01 & 0.09 \\
\hline & & HLA-DRB3*02:02 & 2720 & AFVTNVNASSSEAFL & 0.01 & 0.15 \\
\hline & & HLA-DRB1*11:01 & 865 & NEFYAYLRKHFSMMI & 0.02 & 0.22 \\
\hline & & $\begin{array}{c}\text { HLA- } \\
\text { DQA1*05:01/DQB1*02:01 }\end{array}$ & 2390 & QMEIDFLELAMDEFI & 0.03 & 0.61 \\
\hline & & HLA-DRB3*02:02 & 2755 & NYIFWRNTNPIQLSS & 0.04 & 0.92 \\
\hline
\end{tabular}




\begin{tabular}{ccccccc}
\hline & $\begin{array}{c}\text { HLA- } \\
\text { DQA1*05:01/DQB1*02:01 }\end{array}$ & 2393 & IDFLELAMDEFIERY & 0.05 & 0.25 \\
\cline { 2 - 6 } & $\begin{array}{c}\text { HLA- } \\
\text { DPA1*02:01/DPB1*14:01 }\end{array}$ & 663 & QMNLKYAISAKNRAR & 0.07 & 1.5 \\
\hline
\end{tabular}

2 
Table 3 (on next page)

Table 3

Table 3. Analysis of MHC II epitopes allergenicity and toxicity. 
1 Table 3. Analysis of MHC II epitopes allergenicity and toxicity.

\begin{tabular}{|c|c|c|c|c|c|}
\hline $\begin{array}{c}\text { S.N } \\
\text { o }\end{array}$ & Protein Name & start & Peptide & Allergenicity & Toxicity \\
\hline \multirow{5}{*}{1} & \multirow{5}{*}{ ORF8 protein } & 14 & QPYVVDDPCPIHFYS & Allergen & - \\
\hline & & 10 & CTQHQPYVVDDPCPI & Non-allergenic & Non-toxic \\
\hline & & 13 & HQPYVVDDPCPIHFY & Non- allergenic & Non-toxic \\
\hline & & 12 & QHQPYVVDDPCPIHF & Allergen & - \\
\hline & & 11 & TQHQPYVVDDPCPIH & Non-allergenic & Non-toxic \\
\hline \multirow{12}{*}{2} & \multirow{12}{*}{ Surface Glycoprotein } & 98 & KTQSLLIVNNATNVV & Non-allergenic & Non-toxic \\
\hline & & 100 & QSLLIVNNATNVVIK & Non- allergenic & Non-toxic \\
\hline & & 101 & SLLIVNNATNVVIKV & Non-allergenic & Non-toxic \\
\hline & & 99 & TQSLLIVNNATNVVI & Non- allergenic & Non-toxic \\
\hline & & 100 & QSLLIVNNATNVVIK & Non-allergenic & Non-toxic \\
\hline & & 498 & LSFELLHAPATVCGP & Non- allergenic & Non-toxic \\
\hline & & 497 & VLSFELLHAPATVCG & Non-allergenic & Non-toxic \\
\hline & & 496 & VVLSFELLHAPATVC & Non- allergenic & Non-toxic \\
\hline & & 97 & SKTQSLLIVNNATNV & allergenic & - \\
\hline & & 101 & SLLIVNNATNVVIKV & Non-allergenic & Non-toxic \\
\hline & & 99 & TQSLLIVNNATNVVI & Non- allergenic & Non-toxic \\
\hline & & 495 & VVVLSFELLHAPATV & Non-allergenic & Non-toxic \\
\hline \multirow{6}{*}{3} & \multirow{6}{*}{ ORF1ab polyprotein } & 20 & KSAFYILPSIISNEK & Non-allergenic & Non-toxic \\
\hline & & 2165 & CTNYMPYFFTLLLQL & allergenic & - \\
\hline & & 1801 & ESPFVMMSAPPAQYE & Non-allergenic & Non-toxic \\
\hline & & 2390 & QMEIDFLELAMDEFI & Non- allergenic & Non-toxic \\
\hline & & 2755 & NYIFWRNTNPIQLSS & Non-allergenic & Non-toxic \\
\hline & & 663 & QMNLKYAISAKNRAR & Non-allergenic & Non-toxic \\
\hline
\end{tabular}

2

3 


\section{Table 4 (on next page)}

\section{Table 4}

Table 4. Comparative analysis of B cell epitope using IEDB and ABCpred server and antigenicity analysis. 
1 Table 4. Comparative analysis of B cell epitope using IEDB and ABCpred server and antigenicity analysis.

\begin{tabular}{|c|c|c|c|c|c|c|c|}
\hline $\begin{array}{l}\text { S. } \\
\text { N. }\end{array}$ & Protein name & Start & Epitope IEDB BepiPred & $\begin{array}{l}\text { Antigenici } \\
\text { ty }\end{array}$ & ABCpred & Start & $\begin{array}{c}\text { Antig } \\
\text { enicit } \\
y\end{array}$ \\
\hline \multirow{2}{*}{1} & \multirow{2}{*}{ ORF8 protein } & 12 & QHQPYVVDDP & 0.4127 & PYVVDDPCPIHFYSKW & 15 & 0.56 \\
\hline & & 49 & EAGSKSPI & 0.2081 & ELCVDEAGSKSPIQYI & 44 & -0.18 \\
\hline \multirow{2}{*}{2} & \multirow{2}{*}{ ORF7a protein } & 18 & EPCSSGTYEGNSPFHPLAD & 0.39 & SGTYEGNSPFHPLADN & 22 & 0.29 \\
\hline & & 58 & HVYQLRARSVSPKLFIRQE & 0.59 & HVYQLRARSVSPKLFI & 58 & 0.43 \\
\hline 3 & $\begin{array}{l}\text { membrane } \\
\text { glycoprotein }\end{array}$ & 7 & TITVEELKK & 0.57 & DSNGTITVEELKKLLE & 3 & 0.07 \\
\hline 4 & $\begin{array}{l}\text { envelope } \\
\text { protein }\end{array}$ & 23 & YSRVKNLNSSRVP & 0.47 & YVYSRVKNLNSSRVPD & 21 & 0.54 \\
\hline \multirow{2}{*}{5} & \multirow{2}{*}{ ORF3a protein } & 15 & LKQGEIKDATPSDFVR & 0.81 & QGEIKDATPSDFVRAT & 17 & 0.91 \\
\hline & & & & & IGTVTLKQGEIKDATP & 10 & 1.22 \\
\hline \multirow{17}{*}{6} & \multirow{17}{*}{$\begin{array}{c}\text { surface } \\
\text { glycoprotein }\end{array}$} & 55 & VSGTNGTKRF & 0.53 & HRSYLTPGDSSSGWTA & 230 & 0.6 \\
\hline & & 123 & $\begin{array}{c}\text { DPFLGVYYHKNNKSWMESE } \\
\text { FRVYSSA }\end{array}$ & 0.49 & TVEKGIYQTSNFRVQP & 292 & 0.67 \\
\hline & & 234 & LTPGDSSSGWTA & 0.68 & GCLIGAEHVNNSYECD & 633 & 0.84 \\
\hline & & 298 & YQTSNFRVQP & 1.18 & LQSYGFQPTNGVGYQP & 477 & 0.52 \\
\hline & & 315 & $\begin{array}{c}\text { PNITNLCPFGEVFNATRFASV } \\
\text { YAWNRKRISNC }\end{array}$ & 0.47 & TEIYQAGSTPCNGVEG & 455 & -0.01 \\
\hline & & 389 & GDEVRQIAPGQTGKIAD & 1.06 & KQIYKTPPIKDFGGFN & 771 & -0.22 \\
\hline & & 441 & $\begin{array}{c}\text { FRKSNLKPFERDISTEIYQAGS } \\
\text { TPCNGVEGFNCYFPLQSYGF } \\
\text { QPT }\end{array}$ & 0.39 & CGPKKSTNLVKNKCVN & 510 & 0.2 \\
\hline & & 501 & $\begin{array}{c}\text { ELLHAPATVCGPKKSTNLVK } \\
\mathrm{N}\end{array}$ & 0.0029 & FERDISTEIYQAGSTP & 449 & -0.29 \\
\hline & & 619 & RVYSTGSNVFQ & -0.1 & SWMESEFRVYSSANNC & 136 & 0.17 \\
\hline & & 641 & VNNSYECDIPI & 0.6124 & EVRQIAPGQTGKIADY & 391 & 1.38 \\
\hline & & 657 & ASYQTQTNSPRRARSVASQ & 0.2556 & TPTWRVYSTGSNVFQT & 615 & 0.18 \\
\hline & & 680 & YTMSLGAENSVAYSNN & 0.6434 & VIGIVNNTVYDPLQPE & 1114 & 0.71 \\
\hline & & 771 & KQIYKTPPIKDFGGF & -0.3896 & SQSIIAYTMSLGAENS & 674 & 0.56 \\
\hline & & 792 & PDPSKPSKR & 0.478 & VSGTNGTKRFDNPVLP & 55 & 0.51 \\
\hline & & 1093 & NFYEPQIITTD & 0.36 & FPNITNLCPFGEVFNA & 314 & 0.6 \\
\hline & & 1118 & $\begin{array}{l}\text { VNNTVYDPLQPELDSFKEEL } \\
\text { DKYFKNHTSPDVDLGDISG }\end{array}$ & 0.13 & SQILPDPSKPSKRSFI & 788 & 0.26 \\
\hline & & & & & YQTQTNSPRRARSVAS & 659 & 0.192 \\
\hline \multirow{8}{*}{7} & \multirow{8}{*}{$\begin{array}{c}\text { orf1ab } \\
\text { polyprotein }\end{array}$} & 373 & CHNSEVGPEH & 1.14 & VVKIYCPACHNSEVGP & 365 & 0.76 \\
\hline & & 763 & LQPLEQPTSEAVEAP & 0.05 & TLKGGAPTKVTFGDDT & 814 & 0.98 \\
\hline & & 813 & FTLKGGAP & 0.88 & TSRYWEPEFYEAMYTP & 3996 & 0.4 \\
\hline & & 1458 & NLEEAAR & -0.14 & AVTAYNGYLTSSSKTP & 1482 & 0.35 \\
\hline & & 1482 & AVTAYNGYLTSSSKTPEE & 0.5 & LNLEEAARYMRSLKVP & 1457 & 0.33 \\
\hline & & 2241 & FSSEIIGYKAI & 0.26 & SEAVEAPLVGTPVCIN & 771 & 0.74 \\
\hline & & 3072 & GCSCDQLREPMLQSADAQS & 0.92 & CGMWKGYGCSCDQLRE & 3065 & 0.17 \\
\hline & & 3993 & NDNTSRYWEP & 0.27 & SSEIIGYKAIDGGVTR & 2242 & 0.74 \\
\hline
\end{tabular}




\section{Table 5 (on next page)}

Table 5

Table 5: Analysis of antigenic epitope's allergenicity and toxicity 
1 Table 5: Analysis of antigenic epitope allergenicity and toxicity

2

\begin{tabular}{|c|c|c|c|c|c|c|c|c|c|}
\hline $\begin{array}{l}\text { S. } \\
\text { No }\end{array}$ & $\begin{array}{l}\text { Protein } \\
\text { name }\end{array}$ & Start & epitope IEDB bepipred & $\begin{array}{l}\text { Allergenici } \\
\text { ty }\end{array}$ & Toxicity & ABCpred & Start & $\begin{array}{l}\text { Allergeni } \\
\text { city }\end{array}$ & Toxicity \\
\hline 1 & ORF8 protein & 12 & QHQPYVVDDP & Allergenic & - & $\begin{array}{l}\text { PYVVDDPCPIHFYS } \\
\text { KW }\end{array}$ & 15 & $\begin{array}{l}\text { Non- } \\
\text { allergenic }\end{array}$ & \\
\hline 2 & $\begin{array}{l}\text { ORF7a } \\
\text { protein }\end{array}$ & 58 & $\begin{array}{l}\text { HVYQLRARSVSPKLFIR } \\
\text { QE }\end{array}$ & Allergenic & - & $\begin{array}{l}\text { HVYQLRARSVSPK } \\
\text { LFI }\end{array}$ & 58 & Allergen & - \\
\hline 3 & $\begin{array}{l}\text { membrane } \\
\text { glycoprotein }\end{array}$ & 7 & TITVEELKK & Allergenic & - & & & & \\
\hline 4 & $\begin{array}{l}\text { envelope } \\
\text { protein }\end{array}$ & 23 & YSRVKNLNSSRVP & $\begin{array}{l}\text { Non- } \\
\text { Allergenic }\end{array}$ & Non-toxic & $\begin{array}{l}\text { YVYSRVKNLNSSR } \\
\text { VPD }\end{array}$ & 21 & Allergen & - \\
\hline \multirow[t]{2}{*}{5} & \multirow[t]{2}{*}{$\begin{array}{l}\text { ORF3a } \\
\text { protein }\end{array}$} & 15 & LKQGEIKDATPSDFVR & $\begin{array}{l}\text { Non- } \\
\text { Allergenic }\end{array}$ & Non-toxic & $\begin{array}{l}\text { QGEIKDATPSDFVR } \\
\text { AT }\end{array}$ & 17 & Allergen & - \\
\hline & & & & & & $\begin{array}{l}\text { IGTVTLKQGEIKDA } \\
\text { TP }\end{array}$ & 10 & Allergen & - \\
\hline \multirow[t]{10}{*}{6} & \multirow[t]{10}{*}{$\begin{array}{l}\text { surface } \\
\text { glycoprotein }\end{array}$} & 55 & VSGTNGTKRF & $\begin{array}{l}\text { Non- } \\
\text { Allergenic }\end{array}$ & Non-toxic & $\begin{array}{l}\text { HRSYLTPGDSSSGW } \\
\text { TA }\end{array}$ & 230 & $\begin{array}{l}\text { Non- } \\
\text { allergenic } \\
\end{array}$ & $\begin{array}{l}\text { Non- } \\
\text { toxic }\end{array}$ \\
\hline & & 123 & $\begin{array}{l}\text { DPFLGVYYHKNNKSW } \\
\text { MESEFRVYSSA }\end{array}$ & $\begin{array}{l}\text { Non- } \\
\text { Allergenic }\end{array}$ & Non-toxic & $\begin{array}{l}\text { TVEKGIYQTSNFRV } \\
\text { QP }\end{array}$ & 292 & Allergen & - \\
\hline & & 234 & LTPGDSSSGWTA & $\begin{array}{l}\text { Non- } \\
\text { Allergenic }\end{array}$ & Non-toxic & $\begin{array}{l}\text { GCLIGAEHVNNSYE } \\
\text { CD }\end{array}$ & 633 & $\begin{array}{l}\text { Non- } \\
\text { allergenic }\end{array}$ & Toxic \\
\hline & & 298 & YQTSNFRVQP & Allergenic & - & $\begin{array}{l}\text { LQSYGFQPTNGVG } \\
\text { YQP }\end{array}$ & 477 & $\begin{array}{l}\text { Non- } \\
\text { allergenic }\end{array}$ & $\begin{array}{l}\text { Non- } \\
\text { toxic }\end{array}$ \\
\hline & & 315 & $\begin{array}{l}\text { PNITNLCPFGEVFNATR } \\
\text { FASVYAWNRKRISNC }\end{array}$ & Allergenic & - & $\begin{array}{l}\text { EVRQIAPGQTGKIA } \\
\text { DY }\end{array}$ & 391 & $\begin{array}{l}\text { Non- } \\
\text { allergenic }\end{array}$ & $\begin{array}{l}\text { Non- } \\
\text { toxic }\end{array}$ \\
\hline & & 389 & $\begin{array}{l}\text { GDEVRQIAPGQTGKIA } \\
\text { D }\end{array}$ & $\begin{array}{l}\text { Non- } \\
\text { Allergenic }\end{array}$ & Non-toxic & $\begin{array}{l}\text { TPTWRVYSTGSNV } \\
\text { FQT }\end{array}$ & 615 & $\begin{array}{l}\text { Non- } \\
\text { allergenic }\end{array}$ & $\begin{array}{l}\text { Non- } \\
\text { toxic }\end{array}$ \\
\hline & & 641 & VNNSYECDIPI & $\begin{array}{l}\text { Non- } \\
\text { Allergenic }\end{array}$ & Non-toxic & $\begin{array}{l}\text { VIGIVNNTVYDPLQ } \\
\text { PE }\end{array}$ & 1114 & $\begin{array}{l}\text { Non- } \\
\text { allergenic }\end{array}$ & $\begin{array}{l}\text { Non- } \\
\text { toxic }\end{array}$ \\
\hline & & 680 & $\begin{array}{l}\text { YTMSLGAENSVAYSN } \\
\mathrm{N}\end{array}$ & $\begin{array}{l}\text { Non- } \\
\text { Allergenic }\end{array}$ & Non-toxic & $\begin{array}{l}\text { SQSIIAYTMSLGAE } \\
\text { NS }\end{array}$ & 674 & $\begin{array}{l}\text { Non- } \\
\text { allergenic }\end{array}$ & $\begin{array}{l}\text { Non- } \\
\text { toxic }\end{array}$ \\
\hline & & 792 & PDPSKPSKR & $\begin{array}{l}\text { Non- } \\
\text { Allergenic }\end{array}$ & Non-toxic & $\begin{array}{l}\text { VSGTNGTKRFDNP } \\
\text { VLP }\end{array}$ & 55 & Allergen & - \\
\hline & & & & & & $\begin{array}{l}\text { FPNITNLCPFGEVFN } \\
\text { A }\end{array}$ & 314 & Allergen & - \\
\hline \multirow[t]{5}{*}{7} & \multirow[t]{5}{*}{$\begin{array}{l}\text { orflab } \\
\text { polyprotein }\end{array}$} & 373 & CHNSEVGPEH & Allergenic & - & $\begin{array}{l}\text { VVKIYCPACHNSEV } \\
\text { GP }\end{array}$ & 365 & $\begin{array}{l}\text { Non- } \\
\text { allergenic }\end{array}$ & $\begin{array}{l}\text { Non- } \\
\text { toxic }\end{array}$ \\
\hline & & 813 & FTLKGGAP & $\begin{array}{l}\text { Non- } \\
\text { Allergenic }\end{array}$ & Non-toxic & $\begin{array}{l}\text { TLKGGAPTKVTFG } \\
\text { DDT }\end{array}$ & 814 & Allergen & - \\
\hline & & 1482 & $\begin{array}{l}\text { AVTAYNGYLTSSSKTP } \\
\text { EE }\end{array}$ & $\begin{array}{l}\text { Non- } \\
\text { Allergenic }\end{array}$ & Non-toxic & $\begin{array}{l}\text { TSRYWEPEFYEAM } \\
\text { YTP }\end{array}$ & 3996 & Allergen & - \\
\hline & & 3072 & $\begin{array}{l}\text { GCSCDQLREPMLQSAD } \\
\text { AQS }\end{array}$ & $\begin{array}{l}\text { Non- } \\
\text { Allergenic }\end{array}$ & Non-toxic & $\begin{array}{l}\text { SEAVEAPLVGTPVC } \\
\text { IN }\end{array}$ & 771 & $\begin{array}{l}\text { Non- } \\
\text { allergenic }\end{array}$ & $\begin{array}{l}\text { Non- } \\
\text { toxic }\end{array}$ \\
\hline & & & & & & $\begin{array}{l}\text { SSEIIGYKAIDGGVT } \\
\mathrm{R}\end{array}$ & 2242 & $\begin{array}{l}\text { Non- } \\
\text { allergenic }\end{array}$ & $\begin{array}{l}\text { Non- } \\
\text { toxic }\end{array}$ \\
\hline
\end{tabular}

3

4

5

6

7

8

9

10

11

12

13

14

15

16

17 


\section{Table 6 (on next page)}

Table 6.

Table 6. Comparative analysis of Final MHC I, MHC II and B cell epitopes. 
1 Table 6. Comparative analysis of Final MHC I, MHC II and B cell epitopes.

2

\begin{tabular}{|c|c|c|c|c|c|c|c|c|c|c|}
\hline $\begin{array}{l}\text { S. } \\
\mathbf{N} \\
\mathbf{0}\end{array}$ & $\begin{array}{l}\text { Protein } \\
\text { Name }\end{array}$ & Start & $\begin{array}{l}\text { B cell Epitopes } \\
\text { (IFNscore) }\end{array}$ & $\begin{array}{l}\text { Cross- } \\
\text { reactivity } \\
\text { with } \\
\text { human }\end{array}$ & $\begin{array}{c}\text { STAR } \\
\mathrm{T}\end{array}$ & $\begin{array}{c}\text { MHC I } \\
\text { Epitopes } \\
\text { (IFNscore) }\end{array}$ & $\begin{array}{c}\text { Cross- } \\
\text { reactiv } \\
\text { ity } \\
\text { with } \\
\text { human }\end{array}$ & Start & $\begin{array}{c}\text { MHC II } \\
\text { Epitopes } \\
\text { (IFNscore) }\end{array}$ & $\begin{array}{l}\text { Cross- } \\
\text { reactivit } \\
\text { y with } \\
\text { human }\end{array}$ \\
\hline 1 & $\begin{array}{c}\text { ORF8 } \\
\text { protein }\end{array}$ & 15 & $\begin{array}{c}\text { PYVVDDPCPIHF } \\
\text { YSKW }(1) \\
\end{array}$ & $\mathrm{NO}$ & & & & 10 & $\begin{array}{c}\text { CTQHQPYVV } \\
\text { DDPCPI(1) }\end{array}$ & $\mathrm{NO}$ \\
\hline 2 & $\begin{array}{c}\text { envelope } \\
\text { protein }\end{array}$ & 23 & $\begin{array}{c}\text { YSRVKNLNSSR } \\
\text { VP(-0.49) }\end{array}$ & $\mathrm{NO}$ & & & & & & \\
\hline 3 & $\begin{array}{l}\text { ORF3a } \\
\text { protein }\end{array}$ & 15 & $\begin{array}{c}\text { LKQGEIKDATPS } \\
\text { DFVR(0.62) }\end{array}$ & $\mathrm{NO}$ & 4 & $\begin{array}{c}\text { MRIFTIGTV(- } \\
0.43)\end{array}$ & $\mathrm{NO}$ & & & \\
\hline \multirow{9}{*}{4} & \multirow{9}{*}{$\begin{array}{c}\text { surface } \\
\text { glycoprotei } \\
\mathrm{n}\end{array}$} & 55 & $\begin{array}{c}\text { VSGTNGTKRF(- } \\
0.75)\end{array}$ & $\mathrm{NO}$ & 242 & $\begin{array}{c}\text { WTAGAAAYY } \\
(0.57)\end{array}$ & $\mathrm{NO}$ & 98 & $\begin{array}{l}\text { KTQSLLIVNN } \\
\text { ATNVV(-0.37) }\end{array}$ & $\mathrm{NO}$ \\
\hline & & 123 & $\begin{array}{c}\text { DPFLGVYYHKN } \\
\text { NKSWMESEFRV } \\
\text { YSSA(3.7) }\end{array}$ & $\mathrm{NO}$ & & & & 498 & $\begin{array}{c}\text { LSFELLHAPA } \\
\text { TVCGP }(-0.51)\end{array}$ & $\mathrm{NO}$ \\
\hline & & 234 & $\begin{array}{c}\text { LTPGDSSSGWT } \\
\mathrm{A}(-0.14)\end{array}$ & $\mathrm{NO}$ & - & - & - & - & - & - \\
\hline & & 641 & $\begin{array}{c}\text { VNNSYECDIPI(1 } \\
\text { ) }\end{array}$ & $\mathrm{NO}$ & - & - & - & - & - & - \\
\hline & & 680 & $\begin{array}{c}\text { YTMSLGAENSV } \\
\text { AYSNN(-0.04) }\end{array}$ & $\mathrm{NO}$ & - & - & - & & - & - \\
\hline & & 792 & $\begin{array}{c}\text { PDPSKPSKR }(0.12 \\
)\end{array}$ & $\mathrm{NO}$ & - & - & - & - & - & - \\
\hline & & 477 & $\begin{array}{c}\text { LQSYGFQPTNG } \\
\text { VGYQP(14) }\end{array}$ & $\mathrm{NO}$ & & & & & & \\
\hline & & 391 & $\begin{array}{c}\text { EVRQIAPGQTG } \\
\text { KIADY }(1)\end{array}$ & $\mathrm{NO}$ & & & & & & \\
\hline & & 1114 & $\begin{array}{c}\text { VIGIVNNTVYDP } \\
\text { LQPE(12) }\end{array}$ & $\mathrm{NO}$ & & & & & & \\
\hline \multirow{6}{*}{5} & \multirow{6}{*}{$\begin{array}{c}\text { orf1ab } \\
\text { polyprotei } \\
\mathrm{n}\end{array}$} & 365 & $\begin{array}{c}\text { VVKIYCPACHN } \\
\text { SEVGP(2) }\end{array}$ & $\mathrm{NO}$ & 3841 & $\begin{array}{c}\text { LSDDAVVCF(- } \\
0.30)\end{array}$ & $\mathrm{NO}$ & 20 & $\begin{array}{c}\text { KSAFYILPSIIS } \\
\text { NEK(0.33) }\end{array}$ & $\mathrm{NO}$ \\
\hline & & 771 & $\begin{array}{c}\text { SEAVEAPLVGTP } \\
\text { VCIN(2) }\end{array}$ & $\mathrm{NO}$ & 2413 & $\begin{array}{c}\text { VVTTFDSEY(- } \\
0.51)\end{array}$ & $\mathrm{NO}$ & 1801 & $\begin{array}{c}\text { ESPFVMMSAP } \\
\text { PAQYE(-0.21) }\end{array}$ & $\mathrm{NO}$ \\
\hline & & 2242 & $\begin{array}{c}\text { SSEIIGYKAIDGG } \\
\text { VTR(2) }\end{array}$ & $\mathrm{NO}$ & 295 & $\begin{array}{c}\text { FMGRIRSVY(- } \\
0.25)\end{array}$ & $\mathrm{NO}$ & 2390 & $\begin{array}{c}\text { QMEIDFLELA } \\
\text { MDEFI(0.31) }\end{array}$ & $\mathrm{NO}$ \\
\hline & & 813 & $\begin{array}{c}\text { FTLKGGAP(- } \\
0.22) \\
\end{array}$ & $\mathrm{NO}$ & 4615 & $\begin{array}{c}\text { LQAENVTGL(- } \\
0.21)\end{array}$ & $\mathrm{NO}$ & 2755 & $\begin{array}{c}\text { NYIFWRNTNP } \\
\text { IQLSS(-0.27) }\end{array}$ & $\mathrm{NO}$ \\
\hline & & 1482 & $\begin{array}{c}\text { AVTAYNGYLTS } \\
\text { SSKTPEE(-0.04) }\end{array}$ & $\mathrm{NO}$ & 2166 & $\begin{array}{c}\text { NYMPYFFTL(- } \\
0.58) \\
\end{array}$ & $\mathrm{NO}$ & 663 & $\begin{array}{c}\text { QMNLKYAISA } \\
\text { KNRAR(1) }\end{array}$ & $\mathrm{NO}$ \\
\hline & & 3072 & $\begin{array}{l}\text { GCSCDQLREPM } \\
\text { LQSADAQS }(0.41)\end{array}$ & $\mathrm{NO}$ & 5406 & $\begin{array}{c}\text { FELEDFIPM(- } \\
0.28)\end{array}$ & $\mathrm{NO}$ & & & \\
\hline
\end{tabular}

3

4

5

6

7

8 
Table 7 (on next page)

Table 7

Table 7. Sequence, Antigenicity, and Allergenicity of designed multi-epitope Vaccine constructs. 
1 Table 7. Sequence, Antigenicity, and Allergenicity of designed multi-epitope Vaccine constructs.

\begin{tabular}{|c|c|c|c|c|}
\hline $\begin{array}{l}\text { S. } \\
\text { N } \\
\text { o }\end{array}$ & Name & Vaccine construct & $\begin{array}{c}\text { Antigen } \\
\text { icity }\end{array}$ & Allergenicity \\
\hline 1 & VTC1 & $\begin{array}{l}\text { EAAAKCTQHQPYVVDDPCPIHEYGAEALERAGYSRVKNLNSSRVPG } \\
\text { GGSMRIFTIGTVHEYGAEALERAGKTQSLLIVNNATNVVGGGSLKQG } \\
\text { EIKDATPSDFVRHEYGAEALERAGWTAGAAAYYGGGSLSFELLHAPA } \\
\text { TVCGPHEYGAEALERAGVSGTNGTKRFGGGSLSDDAVVCFHEYGAE } \\
\text { ALERAGKSAFYILPSIISNEKGGGS VVKIYCPACHNSEVGPEAAAK }\end{array}$ & 0.51 & Non-allergenic \\
\hline 2 & VTC2 & $\begin{array}{l}\text { EAAAKCTQHQPYVVDDPCPIHEYGAEALERAGYSRVKNLNSSRVPE } \\
\text { AAAKLKQGEIKDATPSDFVRHEYGAEALERAGMRIFTIGTVEAAAKK } \\
\text { TQSLLIVNNATNVVHEYGAEALERAGDPFLGVYYHKNNKSWMESEF } \\
\text { RVYSSAEAAAKWTAGAAAYYHEYGAEALERAGPDPSKPSKREAAAK } \\
\text { NYIFWRNTNPIQLSSHEYGAEALERAG SSEIIGYKAIDGGVTREAAAK } \\
\text { LQAENVTGL }\end{array}$ & 0.47 & Non-allergenic \\
\hline 3 & VTC3 & $\begin{array}{l}\text { EAAAKGCSCDQLREPMLQSADAQSHEYGAEALERAGFELEDFIPME } \\
\text { AAAKQMNLKYAISAKNRARHEYGAEALERAGEVRQIAPGQTGKIAD } \\
\text { YEAAAKLSFELLHAPATVCGPHEYGAEALERAGWTAGAAAYYEAA } \\
\text { AKLKQGEIKDATPSDFVRHEYGAEALERAGMRIFTIGTVEAAAKYSR } \\
\text { VKNLNSSRVPHEYGAEALERAG PYVVDDPCPIHFYSKWEAAAK }\end{array}$ & 0.61 & Non-allergenic \\
\hline
\end{tabular}

2 
Table 8(on next page)

Table 8

Table 8. Molecular docking of vaccine construct with different TLRs and HLA alleles. 
Table 8. Molecular docking of vaccine construct with different TLRs and HLA alleles.

\begin{tabular}{|c|c|c|c|}
\hline S.No. & Receptor & Receptor PDB & Global Energy \\
\hline \multirow{11}{*}{1} & \multirow{11}{*}{ TLR4 } & $2 Z 62$ & -1.64 \\
\hline & & 3UL8 & 2.16 \\
\hline & & $2 Z 63$ & -28.76 \\
\hline & & 3UL9 & -1.43 \\
\hline & & $2 Z 65$ & -18.55 \\
\hline & & $2 Z 66$ & -23.62 \\
\hline & & 3FXI & -6.93 \\
\hline & & 3ULA & -1.75 \\
\hline & & $4 \mathrm{G} 8 \mathrm{~A}$ & -2.65 \\
\hline & & 5NAM & -6.18 \\
\hline & & $2 Z 64$ & 1.23 \\
\hline \multirow{4}{*}{2} & \multirow{4}{*}{ TLR1-2 hetero dimer } & $2 Z 81$ & -0.88 \\
\hline & & $2 Z 80$ & -31.20 \\
\hline & & $2 Z 82$ & 0.22 \\
\hline & & $2 Z 7 X$ & 3.75 \\
\hline \multirow{2}{*}{3} & \multirow{2}{*}{ TLR1 } & $6 \mathrm{NIH}$ & -1.95 \\
\hline & & 1FYV & -6.49 \\
\hline 4 & TLR2 & $6 \mathrm{NIG}$ & 10.81 \\
\hline 5 & TLR6 & 3A79 & -13.05 \\
\hline \multirow{2}{*}{6} & \multirow{2}{*}{ TLR3 } & $2 \mathrm{~A} 0 \mathrm{Z}$ & -8.85 \\
\hline & & $1 \mathrm{ZIW}$ & 6.11 \\
\hline \multirow{10}{*}{7} & \multirow{10}{*}{ HLA Alleles } & 5IM7 & -24.66 \\
\hline & & 1XR8 & -1.95 \\
\hline & & 1SYS & -17 \\
\hline & & $1 \mathrm{~A} 6 \mathrm{~A}$ & -5.59 \\
\hline & & $1 \mathrm{~A} 1 \mathrm{M}$ & -3.24 \\
\hline & & $1 \mathrm{BX} 2$ & 6.09 \\
\hline & & $1 \mathrm{H} 15$ & -9.32 \\
\hline & & 1ZSD & 5.51 \\
\hline & & $3 \mathrm{C} 5 \mathrm{~J}$ & 5.12 \\
\hline & & $4 \mathrm{O} 2 \mathrm{E}$ & 9.68 \\
\hline
\end{tabular}

